\title{
A novel wake energy reuse method to optimize the layout for Savonius-type vertical axis wind turbines
}

\author{
Baoshou Zhang, ${ }^{1}$ Baowei Song, Zhaoyong Mao, Wenlong Tian \\ School of Marine Science and Technology, Northwestern Polytechnical University \\ No. 127, Youyi Road(West), Beilin, Xi'an City, Shaanxi Province, PRC
}

\begin{abstract}
The long wake of a wind turbine has a significant impact on the performance of downstream turbines. Under the inspiration of migrating geese flying in a V or I formation to save energy, a novel wake energy reuse method is proposed to optimize the layout for Savonius-type vertical axis wind turbines (S-VAWT). VAWT wakes include a series of high speed and energy zones. On both sides of the upstream turbine, $7 \times 16$ transient two-dimensional numerical simulations are performed with Fluent to investigate wake structure, interaction effect and power coefficients $\left(C_{\mathrm{p}}\right)$ of downstream turbines. Based on Kriging Method, a response surface model (Surrogate model) is created to describe the relationship between the optimization objective $C_{\mathrm{p}}$ and layout positions. Finally, particle swarm optimization algorithm is applied to find the optimal relative layout position $(5.25 \mathrm{~m},-2.18 \mathrm{~m})$ of the downstream turbine. The optimal position is located in the periodic high speed zone of the wake on the advancing blade side. And the optimal position is suitable for multi-turbines in a large wind farm. The optimization results show that $C_{\mathrm{p}}$ of downstream turbines at optimal layout position is significantly increased from 0.2477 to 0.3044 (22.89\% higher).
\end{abstract}

\section{KEYWORDS}

Savonius-type vertical axis wind turbines; Wake; Layout; Numerical simulation; Interaction effect

\section{INTRODUCTION}

The gradually exhausting non-renewable energy resources have stimulated the development of the renewable energy technology. Wind is an important renewable energy source. Recently, a new challenge arises in the design of the wind turbine layout. The wake of the upstream turbine has a detrimental effect in a wind farm. In the turbine wake, wind speed decreases, while the turbulence intensity increases. These effects result in a large disturbance for downstream wind turbines. Previous studies have found that uneven load stress appears on downstream wind turbines, and such fatigue load will reduce the life of turbines. $[1,2,3]$ Meanwhile, the unsteady wake will deteriorate the performance of downstream wind turbines, which further reduces the economic efficiency of a wind farm. According to previous work, $10-20 \%$ of the total power output of large wind farms will be wasted [2]. Thus, it is quite meaningful to study the wake to wake interaction and the characteristics of the wake. The traditional method for wind turbines layout aims

Corresponding author: Baoshou Zhang, Telephone/fax number: +86 18792547553; E-mail address: $1262034751 @$ qq.com 
to reduce interaction effects between different turbines and increase power. In other words, the wake of the upstream turbine should not overlap with the downstream turbine [1]. Other researches have shown that increasing the number of turbines could appropriately improve the economic efficiency in equal surfaces $[2,4,5]$. However, there are no public literatures relating to the reuse of the wake energy to enhance the performance of downstream turbines. And the relationship between the layout position and the performance of vertical axis wind turbine has not been investigated in detail. Therefore, it is essential to conduct research on wind turbines layout optimization for energy efficiency improvement.

This study takes Savonius-type vertical axis wind turbines (S-VAWT) as an example. S-VAWT is a type of vertical axis wind turbines. Main advantages of S-VAWTs can be described as follows:

- High starting up and full operation moment [6]

- Operation in a wide range of wind conditions

- Simple construction and low noise emission $[7,8]$

These advantages make S-VAWTs suitable for small and medium-sized distributed power generation. In general, this power generation is between tens of $\mathrm{kW}$ and hundreds of $\mathrm{kW}$. Wind energy utilization efficiency of S-VAWTS is $15-25 \%$ in past simulations and experiments [6,8]. There is still room to improve the relatively low efficiency. For S-VAWTs, after the wind bypasses blades, the incoming flow becomes more complicated. According to previous studies $[9,10,11,12]$, the performance of the downstream turbine is deteriorated by the wake, and therefore the distance between two S-VAWTs should be large enough to reduce the wake effect. The distance for VAWT is usually 15 times larger than the rotor diameter [1]. The distance limits the maximum number of turbines in equal available surfaces. However, a series of high speed and energy zones are also observed in the wake, and so far few investigations were performed to reuse the wake energy of upstream turbines. Thus, a novel wake energy reuse method is proposed for the turbine layout optimization in the current work. Downstream turbines are placed in the high speed and energy zones of the wake to reuse the wake energy. The results show that, compared with the traditional layout, the wind turbine distances are far less, i.e., the number of turbines increases in equal surfaces, and the downstream turbine acquires a higher efficiency.

Optimization method is essential in the current work to find the optimal turbine layout. Considering the large number of design schemes and the complexity of the wake, wind tunnel experiments are difficult to implement, while numerical method is efficient and intuitive $[4,6]$. To obtain the optimal solution for the turbine layout, a series of transient CFD simulations is performed to investigate different layout characteristics with Fluent. Surrogate model is always used in the optimization process when the evaluation of the objective function is time-consuming, as in the current problem. Kriging Method proposed by Danie G. Krige in 1951 is a widely used surrogate model to establish the response surface [13]. The relationship (response surface model) between optimization objective (energy efficiency) and layout positions could be precisely defined based on Kriging model.

Then, a highly effective optimization method is needed to find the optimal solution based on Kriging model. Particle swarm optimization (PSO) algorithm is an optimization method that is simple in concept, easy to be implemented and computationally inexpensive [14]. Accordingly, the PSO algorithm is adopted to find the optimal relative position of the downstream turbine. The optimal layout position of the 
downstream turbine is obtained through a series of iterations. Energy distributions, typical velocity distributions, pressure distributions around different blades and interaction effect of multi-turbines are also illustrated and analyzed. Compared with traditional layout, the proposed optimal layout has significant improvements. The power coefficient $C_{\mathrm{p}}$ of downstream turbines is increased by $22.89 \%$. And the distance between the upstream turbine and the downstream turbine is obviously reduced. So in equal surfaces, the number of turbines using the new layout method is about 4 times the number of turbines using past no overlap layout method.

The main contribution of the paper is that a new way to regard the turbine's wake is proposed. The high speed zone in the wake created by the upstream turbine is exploited to improve the performance of downstream turbines. It is a completely new thought to optimize the layout of S-VAWTs. This novel layout method has both theoretical and practical values, and gives a new idea for further development of wind energy utilization.

\section{GEOMETRY CONFIGURATION}

As known to all, migrating geese fly in a V or I formation, as shown in Fig. 1(a). The goose in front produces high speed updrafts in wake, so downstream geese fly in updrafts or use the pressure difference to save energy. Similarly, upstream turbine produces a long wake and a periodic high speed zone on both sides of the wake. As the upstream turbine rotates, high speed rotating vortices appear behind the blades [11]. The periodic high speed zone appears accordingly. The velocity difference and the high speed zone could be used to enhance the performance of downstream turbines.

In particular, there are two types of layout positions for each downstream turbine. Type I: locating returning blade in low speed zone but advancing blade in periodic high speed zone, as shown in Fig. 1(b) Type I position. Type II: locating two blades in the periodic high speed zone, as shown in Fig.1(b) Type II position. This difference will be discussed in detail in following sections.

VAWT is a type of drag-driven devices. [6] Advancing blade which moves in the same direction with flow provides thrust, while returning blade which moves in the opposite direction with flow provides drag. Generally, downstream turbines could be arranged into one side type layout (on advancing blade side or returning blade side) or $\mathrm{V}$ type layout (on both sides), as shown in Fig. 2.

Geometric model of S-VAWT is shown in Fig. 3(a). According to previous studies [6,7,15], a simplified two-dimensional model can be used to describe the wind turbine, as shown in Fig. 3(b). Some parameters are necessary to define the turbine profile, as listed in Table 1. D is the turbine diameter; $H$ is the turbine height; $d$ is the length of the blade; $r$ is the radius of the blade; $S_{0}$ is the length of blades overlap. These turbines are exposed to the wind with the rotation rate $\omega$. The undisturbed wind speed is $v_{\infty}$. [15,16]

Tip speed ratio (TSR) means the ratio between blade tip speed and inflow air speed, i.e., TSR is defined as Eq. (1):

$$
T S R=\omega D /\left(2 v_{\infty}\right)
$$

The performance of a turbine can be characterized by using the two main indicators: torque coefficient $\left(C_{\mathrm{T}}\right)$ and power coefficient $\left(C_{p}\right) . C_{p}$ represents the fraction of extracted power from the total power of air 
flow which runs through the projected area of the turbine at the flow direction. $C_{\mathrm{T}}$ and $C_{p}$ can be obtained as follows:

$$
\begin{gathered}
C_{T}=4 M /\left(\rho H v_{\infty}^{2} D^{2}\right) \\
C_{p}=P /\left(0.5 \rho H D v_{\infty}^{3}\right)=C_{m} \cdot T S R
\end{gathered}
$$

where $M$ is the torque acting on turbines; $P$ is the power of the turbine; $\omega$ is the rotational speed; $\rho$ is the density of water. Since only two-dimensional simulations are performed, the height $H$ of turbines is $1 \mathrm{~m}$. [17]

Generally, power coefficient $C_{p}$ is used to evaluate the comprehensive performance of Savonius turbines. In this paper, the optimization objective is to attain the best $C_{p}$ by locating the downstream turbine at the optimal position in the wake.

\section{NUMERICAL METHOD}

Numerical simulation is a precise and high-efficient investigation approach for the wake flow. A series of two-dimensional representations of the flow field is built. Hence, the flow in the vertical direction is neglected, which is equivalent to 3D Savonius turbines with endplates. It has been already successfully proved in similar studies by using Fluent [6,17-19]. Then, the results of the numerical simulation are validated and compared with some previous typical experimental data. The results of these two methods are in good agreement, as will be discussed in the upcoming sections.

In the optimization process, numerical method using Fluent provides fundamental elements for the modeling of the response surface surrogate model (established by using Kriging Method). Numerical method could simulate wake flow around the turbines. Correspondingly, fluid forces/moments/ angular velocities/ etc. acting on these turbines are obtained separately. Meanwhile, the performances $\left(C_{\mathrm{p}}\right.$ power coefficient) of the turbines are obtained. For a certain relative position between the upstream turbine and the downstream turbine, a certain performance of the turbine is obtained. In other words, Fluent translates the information of layout position $(x, y)$ into the performance $\left(C_{\mathrm{p}}\right.$ power coefficient $)$ of the turbine. Then, Kriging Method establishes the relation model (Surrogate model) between a series of $C_{\mathrm{p}}$ and layout positions $(x, y)$. Finally, the optimal value of $C_{\mathrm{p}}$ is found based on PSO and the surrogate model.

\subsection{Computational domains and grid generation}

The computational domain is shown in Fig. 4. A 3-unit layout is a fundamental element of a larger amount of units in a large wind farm. Interaction effect between three turbines is the most representative example. Wind turbines at A and B positions have the same direction of rotation. Relative position between the rotation centers of two turbines at $\mathrm{A}$ or $\mathrm{B}$ positions is $\left(x_{B}, y_{B}\right) .7 \times 16$ schemes are simulated to cover the wake on the advancing blade side. $x_{B}$ changes from $2 \mathrm{~m}$ to $8 \mathrm{~m}$ with a $1 \mathrm{~m}$ interval; $y_{B}$ changes from $-0.4 \mathrm{~m}$ to $-3.4 \mathrm{~m}$ with a $0.2 \mathrm{~m}$ interval. Similarly, relative position between $\mathrm{A}$ and $\mathrm{C}$ positions is $\left(x_{C}, y_{C}\right)$. The wind turbine at $\mathrm{C}$ position rotates in the opposite direction. Wind speed is $7.0 \mathrm{~m} / \mathrm{s}$. The initial conditions are the same as those used in previous studies. [6,17] Simulation results provide basic component factors for 
layout optimization.

Moving mesh technology also known as dynamic mesh technology is used to simulate the rotation of the wind turbine. Rotating domain and local details of the mesh are shown in Fig. 5.

\subsection{Numerical method validation}

In this section, mesh independence validation and time step independence validation are conducted. Mesh independence is tested by assessing the instantaneous $C_{\mathrm{T}}$ of the wind turbine for different mesh densities [20,21]. $C_{\mathrm{T}}$ is presented in Fig. 6(a). Since two blades are origin-symmetric, the instantaneous $C_{\mathrm{T}}$ is cycled twice in a rotation period. The different $C_{\mathrm{T}}$ has the great consistency, though the mesh densities are different (61000/86900/117000 elements). Accordingly, the mesh with approximately 60,000 elements is sufficient for the mesh independence study. And this mesh density is propitious to ensure the higher computation efficiency.

The time step independence validation is conducted using different time steps ranging from 0.5 degrees/step to 4 degrees/step, as shown in Fig. 6(b). The different instantaneous $C_{p}$ ranging from 0.5 degrees/step to 2 degrees/step have the great consistency. Taking the efficiency of simulated into consideration, 1.0 degree/step is selected in the optimization process.

To verify the feasibility of the numerical method, simulation results are compared with wind tunnel experimental data presented by US Sandia Laboratories [22]. Fig. 7 shows the comparison of the average $C_{\mathrm{p}}$ at different TSR for experimental data and simulation data obtained by using this numerical method. The values of averaged power coefficient increase with the TSR. The maximum of averaged power coefficient $\left(C_{\mathrm{p}}=0.2477\right)$ appears at about $T S R=0.8-1.0$. After a certain value, $C_{\mathrm{p}}$ decreases. It is clear that simulation results fit well with the experimental data. Therefore, the numerical method using Fluent is acceptable. The simulation results of the single turbine are used as reference values in the following optimization process.

\subsection{Simulation example}

Velocity distributions and turbulence kinetic energy distributions of the wake are shown in Fig. 8 and Fig. 9. The upstream turbine creates periodic high speed vortex zones and an unsteady flow with increased turbulence. The shedding vortex is stretched with the increase of distance.

In the simulation process, the cyclical $C_{\mathrm{T}}$ during 15 rotation periods is monitored, as shown in Fig. 10(a). The instantaneous $C_{\mathrm{T}}$ cyclically varies with the rotor angle. The variation of $C_{\mathrm{T}}$ of the upstream turbine keeps the same in the sixth and subsequent rotation periods. Due to the wake effect, the variation of $C_{\mathrm{T}}$ of downstream turbines is more complex.

With these coefficient curves, the performance of S-VAWT can be defined and compared, which provides the parameterization basis for the layout optimization. The instantaneous $C_{\mathrm{T}}$ of a single blade is shown in Fig. 10(b). Average power coefficients $\left(C_{\mathrm{p}}\right)$ of different turbines are compared in Fig. 10(c). Ref. value represents $C_{\mathrm{p}}$ of a single wind turbine obtained without considering the effect from other turbines. $C_{\mathrm{p}}$ of the upstream turbine is close to Ref. value $\left(C_{\mathrm{p}}=0.2477\right)$; At B position, the wind turbine is located in the periodic high speed zone. Correspondingly, $C_{\mathrm{p}}$ is improved obviously. At $\mathrm{C}$ position, the returning blade of 
the wind turbine is located in low speed zone, and the advancing blade is located in the periodic high speed zone. However, $C_{\mathrm{p}}$ fells significantly. It means that performance degradation occurs. These layout differences will be discussed in section 5.2.

\section{OPTIMAL DESIGN METHOD}

Generally, particle swarm optimization (PSO) is a method of searching for the optimal value according to a certain known model (Surrogate model). In this paper, the certain known model is established by using Kriging Method. Kriging model describes the relationship between optimization objective $C_{\mathrm{p}}$ and layout positions $(x, y) . C_{\mathrm{p}}$ represents the performance of the downstream turbine. PSO could find the maximum value of $C_{\mathrm{p}}$. Finally, the maximum value of $C_{\mathrm{p}}$ corresponds to the optimal layout position $(x, y)$ of the downstream turbine.

\subsection{Kriging Method}

Numerous adaptations of layout positions ( $x$ and $y$ ) are performed to establish the surrogate model using Kriging Method. Kriging Method defines the relationship between optimization objective $C_{p}$ and layout position parameters accurately. Kriging Method expresses the unknown function $\hat{y}(\mathrm{X})$ as:

$$
\hat{y}(\mathrm{X})=\beta+z(\mathrm{X})
$$

In this paper, $\mathrm{X}$ is a 2-dimensional vector including position parameters $(x$ and $y) ; \beta$ is the linear regression part; $z(\mathrm{X})$ is the local deviation. $z(\mathrm{X})$ represents a model of a Gaussian and stationary random process with zero mean and covariance:

$$
\begin{gathered}
E[z(\mathrm{X})]=0 \\
\operatorname{Var}[z(\mathrm{X})]=\sigma^{2} \\
E\left[z(\mathrm{X}) z\left(\mathrm{X}_{i}\right)\right]=\sigma^{2} R\left(\mathrm{X}, \mathrm{X}_{i}\right)
\end{gathered}
$$

where $\sigma^{2}$ is the variance of the stationary random process; $R\left(\mathrm{X}, \mathrm{X}_{i}\right)$ is the spatial correlation function which represents the correlation between $z(\mathrm{X})$ and $z\left(\mathrm{X}_{i}\right)$. The Spatial Correlation Function $(\mathrm{SCF})$ is defined as:

$$
R\left(\mathrm{X}, \mathrm{X}_{i}\right)=\exp \left[-\sum_{i=1}^{n} \theta_{k}\left(\mathrm{X}_{k i}-\mathrm{X}_{k}\right)^{2}\right]
$$

where $\theta_{k}$ is the kth element of the correlation vector parameter $\theta$. The correlation matrix can be obtained as follows:

$$
R=\left[\begin{array}{ccc}
R\left(\mathrm{X}_{1}, \mathrm{X}_{1}\right) & \cdots & R\left(\mathrm{X}_{1}, \mathrm{X}_{N}\right) \\
\vdots & \ddots & \vdots \\
R\left(\mathrm{X}_{N}, \mathrm{X}_{1}\right) & \cdots & R\left(\mathrm{X}_{N}, \mathrm{X}_{N}\right)
\end{array}\right]
$$

where $R\left(\mathrm{X}_{N}, \mathrm{X}_{N}\right)$ is a SCF of two known points, and each possible combination of these simple points is described by matrix $R$. The correlation between an unknown prediction point $\mathrm{X}$ and the $N$ sample points is defined as follows: 


$$
r(\mathrm{X})=\left[\begin{array}{c}
R\left(\mathrm{X}, \mathrm{X}_{1}\right) \\
\vdots \\
R\left(\mathrm{X}, \mathrm{X}_{N}\right)
\end{array}\right]
$$

The main goal of the paper is to optimize the layout of turbine, so the details of the derivations details are not described here. The final Kriging Method predictor $\hat{y}(\mathrm{X})$ is obtained [13,23]:

$$
\hat{y}(\mathrm{X})=\hat{\beta}+r^{T}(\mathrm{X}) R^{-1}(Y-E(\hat{g}(\mathrm{X})))
$$

where $\hat{\beta}$ is the least-squares estimated of $\beta ; Y$ is $\mathrm{N}$-dimensional vector:

$$
\begin{aligned}
& \hat{\beta}=\left(E^{T} R^{-1} E\right)^{-1} E^{T} R^{-1} Y \\
& Y=\left\{\begin{array}{llll}
y\left(\mathbf{X}_{1}\right) & y\left(\mathbf{X}_{2}\right) & \cdots & y\left(\mathbf{X}_{N}\right)
\end{array}\right\}^{T}
\end{aligned}
$$

This uncertainty of Kriging predictor $\hat{y}(\mathrm{X})$ is expressed as follows.

$$
\begin{aligned}
M S E & =E\left[(\hat{y}(\mathrm{X})-y(\mathrm{X}))^{2}\right] \\
& =\sigma^{2}\left\{1-r^{T}(\mathrm{X}) R^{-1} r(\mathrm{X})+\left[1-E^{T} R^{-1} r(\mathrm{X})\right]^{2}\left(E^{T} R^{-1}\right)^{-1}\right\}
\end{aligned}
$$

where $M S E$ represents the mean squared error of $y(\mathrm{X})$. MATLAB is used for the Kriging Method program writing. Finally, the response surface is built as shown in Fig. 12 and Fig. 13 in the next section.

\subsection{Particle swarm optimization (PSO)}

PSO has been recognized as much effective algorithm both in speed and quality of solution. PSO algorithm possesses the advantages of a simple concept, global optimization performance, and less controlling parameters, et al [24]. Although, when it comes to multivariate problems or sudden changes, it is not validated by a mathematical approach that PSO can ensure optimality. Because it is impossible to set countless sample points to cover global variable space. But for the two-dimensional layout $(x, y)$ in empirical evidence, PSO is suitable for the less optimization variables problem in practice. Great ability in global optimal search and avoiding trapping in local optimum are also attractive. In this paper, PSO satisfies the requirements of optimization. Thus, PSO is adopted to solve the relatively simple two-dimensional optimal layout. The steps of PSO are as follows:

(1) Initialize particles (initial layout position)

In this paper, the number of random particles is 500:

$$
P 1=(x 1, y 1), P 2=(x 2, y 2), P 3=(x 3, y 3) \ldots P 500=(x 500, y 500)
$$

(2) Calculate the fitness value $\left(C_{\mathrm{p}}\right)$ for each particle according to the certain known model $f$ (Surrogate model):

$$
C_{p}=f(x, y)
$$

where $f$ is derived from Kriging Method $\hat{y}(\mathrm{X})$ according to Eq. (11).

(3) Set the particle $P$ i with the best fitness value $\left(C_{\mathrm{p}}\right)$ in history as personal optimal solution ( $\left.p B e s t\right)$.

(4) Choose the particle $P \mathrm{~g}$ with the best fitness value $\left(C_{\mathrm{p}}\right)$ of all the particles as the global optimal solution (gBest). Maximum optimization objective $C_{\mathrm{p}}$ is the best choice of wind turbine layout patterns. Finally, optimal $C_{\mathrm{p}}$ could be converted into the optimal layout position $(x, y)$ according to Kriging model. 
(5) Then, for each particle, calculate particle speed according to Eq. (17) and Eq. (18) in the $x$ and $y$ direction.

$$
\begin{aligned}
& v_{x}=w \times v_{x}+c 1 \times \operatorname{rand}\left(0 \times\left(\text { pBest }_{x}-\text { present }_{x}\right)+c 2 \times \operatorname{rand}() \times\left(\text { gBest }_{x}-\text { present }_{x}\right)\right. \\
& v_{y}=w \times v_{y}+c 1 \times \operatorname{rand}\left(0 \times\left(\text { BBest }_{y}-\text { present }_{y}\right)+c 2 \times \operatorname{rand}() \times\left(\text { BBest }_{y}-\text { present }_{y}\right)\right.
\end{aligned}
$$

where $v_{x}$ and $v_{y}$ are particle speed; pBest $t_{x}$ and pBest $_{y}$ are personal optimal solution; present $_{x}$ and present $_{y}$ are present position. Acceleration coefficient $c 1$ is 2 ; acceleration coefficient $c 2$ is 2 ; the inertia weight $w$ is 0.8 .

(6) Update particle position according Eq. (19) and Eq. (20) per unit time $t$.

$$
\begin{aligned}
& \text { present }_{x}=\text { present }_{x}+v_{x} \times t \\
& \text { present }_{y}=\text { present }_{y}+v_{y} \times t
\end{aligned}
$$

(7) If the maximum number of iterations or minimum error criteria is attained, the optimization process stops. In this paper, the maximum number of iterations is 500, which is set as the stop criterion.

For this two-dimensional layout optimization problem, the constraint is the position and size of these turbines. First, impact is not allowed. The distance between the upstream turbine and the downstream turbine should be greater than the turbine diameter (1D). Then, relative position shall not exceed the range of a turbine wake (15D). All the constraints have been written in the optimization program. The layout optimization program based on the PSO is designed in Fig. 11.

PSO is implemented in a computer program (using Matlab language) in conjunction with Kriging model according to the flow diagram Fig.11. And we have compared PSO with Genetic Algorithm (GA) when choosing an optimization method. In this optimization using PSO, 500 particles are randomly selected. The optimal solution is obtained after about 200-250 iterations. But in the similar cases, GA-based iteration takes up to 2-3 times as long as PSO-based iteration.

In this paper, the optimization program has been repeated for 20 times with different initial particles. Compared with average value, all deviations are mainly in about $0.15 \%-0.18 \%$. Meanwhile, experimental results from practical project fit well with these simulation results. It is clearly that random initial particles and outside initial disturbance is not obvious. All these results prove that the optimization process has high efficiency and strong robustness in practice. The output in this optimization process is the optimal value $C_{p}$. Then, 2 variables representing the $\mathrm{X}$ and $\mathrm{Y}$ coordinates of the downstream turbine's position are translated from Kriging model. Hence, with the help of PSO, the optimal layout solution can be found.

\subsection{Optimization results}

The optimal position of the downstream turbine obtained by the PSO algorithm can effectively enhance the turbine performance. On the returning blade side, the response surface model respecting to the layout positions $(x, y)$ is established, as shown in Fig. 12(a). The response surface represents the energy distributions diagram for the downstream turbine. Two green dashed lines represent reference value $\left(C_{p=0}\right.$.2477). Through the iterative search, the optimal point is directly obtained by using PSO. The optimal point is marked in Fig. 12(b). The coordinate values of the optimal point represent the position of the downstream turbine ( $x=4.91$ and $y=2.24$ ). The predictive value of $C_{\mathrm{p}}$ is 0.29116 . 
Similarly, on the advancing blade side, the response surface model respecting to the layout position ( $x$, $y$ ) is shown in Fig. 13(a). The optimal point found by PSO is marked in Fig. 12(b). The coordinate values of the optimal point represents the layout position of the downstream turbine ( $x=5.25$ and $y=-2.18)$. The predictive value of $C_{\mathrm{p}}$ is 0.30722 . It is clear that the optimal position on the advancing blade side is better than that of on the returning blade side.

\section{RESULTS AND ANALYSIS}

\subsection{Wake structure}

Based on the optimization result in Section 4, the optimal position of the downstream turbine is completely located in the periodic high speed zone, and the optimal layout position on the advancing blade side has a definite advantage. In order to test the accuracy of the layout optimization process, experimental value of $C_{p}$ is used to verify the correctness of the optimal results. Optimal layout positions, predictive value of $C_{p}$, experimental value of $C_{p}$, and optimization effect of are compared in Table 2 below. Experimental value of $C_{p}$ is consistent well with the predictive value of $C_{p}$. It also proves that the optimal layout on the advancing blade side has better performance. Therefore, the optimal layout on the returning blade or $\mathrm{V}$ type layout would not be taken into account.

In order to analyze the advantages of the optimal layout, simplified wake structure is illustrated in Fig. 14. Analogous to flow past circular cylinder, the flow field velocity on both sides of circular cylinder increases due to blockage effect. The wake of the upstream turbine will be separated into 3 parts. The middle part is the main wake flow (Low speed zone). The down part is a periodic high speed zone (on the advancing blade side). Because the blade moves in the same direction with the flow, a lot of periodic high speed zones appear. Therefore, the averaged incoming flow speed for downstream turbines increases. The upper part is a secondary-periodic high speed zone (on the returning blade side). The blade moves in the opposite direction with flow, so it will impede wind. Correspondingly, the secondary-periodic high speed zone appears behind the returning blade. That's the explanation for why the optimal layout position is on the advancing blade side.

\subsection{Typical layout analysis}

The optimal layout position of the downstream turbine is located in periodic high speed zone. However, a special layout position is also noteworthy. Returning blade is located in low speed zone and advancing blade is located in periodic high speed zone. A typical layout is analyzed in detail here. The relative position of the downstream turbine is $x=4 \mathrm{~m}$ and $y=-0.8 \mathrm{~m}$. To explain the interaction between two turbines, the velocity distributions are shown in Fig. 15. Due to the wake effect, the flow structure around the downstream turbine is very complex. A series of vortexes are generated by the upstream turbine. The wake of the upstream turbine is truncated by the downstream turbine, as a result, the wake is divided into two parts. It is clearly seen that different blades of the downstream turbine are affected separately by different flow. Returning blade is affected by low speed flow. Advancing blade is influenced by periodic 
high speed flow.

It was once believed that this type layout is the optimal layout, but in fact it isn't. In order to make a qualitative analysis for the performance of the downstream turbine, instantaneous $C_{\mathrm{T}}$ of turbine is compared with the reference value. Variations of $C_{\mathrm{T}}$ of a single blade are shown in Fig. 16(a) and Fig. 16(b). Two $C_{\mathrm{T}}$ curves of the blades have an obvious difference. Because the returning blade is located in low speed zone, the minimum value of $C_{\mathrm{T}}$ becomes greater compared with the reference value. As for another blade shown in Fig. 16(b), maximum value of instantaneous $C_{\mathrm{T}}$ is reduced. Although, the minimum value of $C_{\mathrm{T}}$ becomes greater, the performance of the blades may be not improved in a whole rotation period. Fig. 16(c) shows the variations of $C_{\mathrm{T}}$ of the downstream turbine (including two blades). Since the two blades are origin-symmetric, $C_{\mathrm{T}}$ of the turbine shows a double peak profile in a rotation period. Average power coefficient $\left(C_{\mathrm{p}}\right)$ is 0.2235 , which is less than the reference value 0.2477 . For this layout method, the wake effect is significantly negative on the downstream turbine. The performance of the whole turbine is not improved in this layout position.

\subsection{Optimal layout analysis}

According to the current results, one side type layout (on the advancing blade side) is the best. The optimal layout position of the downstream turbine is located in the periodic high speed zone where the averaged incoming flow speed for the downstream turbine increases. The flow structure of the downstream turbine is almost the same to that of the upstream turbine, as shown in Fig. 17.

The performance of this optimal layout is validated and compared with the reference value. They all are similar in profile. $C_{\mathrm{T}}$ of the turbine is compared in Fig. 18. Obviously, not only a single blade, but also the whole downstream turbine is significantly improved. Average $C_{\mathrm{p}}$ of the downstream turbine at optimal layout position is increased from 0.2477 to 0.3044 (22.89\% higher).

The conventional multi-turbines layout method focuses much more on reducing the interaction effect between different turbines and increase power. Briefly, the wake of the upstream turbine should not overlap with the downstream turbine. The wake is detrimental to downstream turbines. No overlap distance should be more than 15D in flow direction. And the lateral distance should be more than about 3D. In the current work, downstream turbines are placed in the periodic high speed zone of the wake and reuse the wake energy, as shown in Fig. 17. In flow direction, the distance is about 5.2D. The lateral distance is about 2.1D. The new layout distances are far less than the conventional layout. In equal surfaces, the number of turbines using the new layout method is about 4 times larger than the number of turbines using no overlap layout method.

It is essential to investigate pressure distributions around the wind turbines [25]. At the rotor angle of 0 degrees (Fig. 19(a)), a high pressure zone appears on the concave side of the advancing blade, and a low pressure zone appears on the convex side of the advancing blade. At 45 degrees (Fig. 19(b)), pressure distributions around the advancing blade are similar to that of 0 degrees rotor angle. For the returning blade, a high pressure area appears on the convex side, and a low pressure area appears on the concave side. The pressure differential provides a great torque inhibiting the rotation of the turbine. At 90 degrees (Fig. 19(c)), a great low pressure zone appears on the top of the advancing blade. The pressure difference will increase 
the driving torque. However, the pressure differential on the returning blade creates negative torque inhibiting the rotation of the turbine. At 135 degrees (Fig. 19(d)), a great low pressure vortex leaves the top of the advancing blade. Then, the turbine rotates in these previous steps.

The changing curves of the pressure distributions on a single blade at $0,45,90,135,180$ and 270 degrees are also compared, as shown in Fig. 21(a)-(f). Comparison of pressure distributions on the blade will give a precise explanation where the improvement occurs. The horizontal axis represents the length of the blade (m). The vertical axis represents pressure (Pascal).

Pressure distributions on the concave side of the reference turbine (C-Ref), the convex side of the reference turbine (V-Ref), the concave side of the optimal layout turbine (C-Op) and the convex side of the optimal layout turbine ( $\mathrm{V}-\mathrm{Op}$ ) are drawn. Meanwhile, pressure differential between concave side and convex side of the reference turbine (All-Ref) and the optimal layout turbine (All-Op) are also drawn in Fig. 20. The curve of All-Op is evidently located upper side of the curve of All-Ref in most cases. Therefore, the downstream turbine placed in the optimal layout position is obviously improved.

\subsection{Multi-turbines interaction effect}

Multi-turbines interaction effect should not be ignored. It is inevitable that the downstream turbine impedes the flow and increases blocking ratio $[11,26]$. The performance of the upstream turbine may be affected. Response surface of $C_{\mathrm{p}}$ for the upstream turbine is illustrated in Fig. 21.

The response surface represents the energy distributions diagram of the upstream turbine respecting to the layout position of the downstream turbine. In the region of a green dashed line, $C_{\mathrm{p}}$ is less than the reference value $\left(C_{\mathrm{p}}=0.2477\right)$, which means the interaction effect from downstream turbine can't be ignored. But clearly, the optimal layout position $(x=5.25$ and $y=-2.18)$ is out of the region. The interaction effect on the upstream turbine could be ignored. Under the condition, the optimal layout position can be extended. Compared with past relative essays, multi-turbines layout is more closely spaced. It means that the number of turbines increases. A 5-unit layout or a larger amount of units could be created, as shown in Fig. 22. Five wind turbines are investigated at the same time to validate the optimal position and multi-turbines interaction effect. The wake structure of downstream wind turbines is similar to that of the upstream turbine.

Instantaneous $C_{\mathrm{T}}$ of a single blade are compared in Fig. 23(a). $C_{\mathrm{T}}$ of No.2,3,4,5 turbines are significantly higher than the reference value. Average power coefficients are compared in Fig. 23(b). Correspondingly, $C_{\mathrm{p}}$ of No. 2,3,4,5 turbines are higher than $C_{\mathrm{p}}$ of the upstream turbine. $C_{\mathrm{p}}$ of the upstream turbine is close to reference value. $C_{\mathrm{p}}$ of No. 2,3,4,5 turbines are close to $C_{\mathrm{p}}$ of the downstream turbine at the optimal relative position (predictive value of $C_{\mathrm{p}}$ is 0.30722 ).

Meanwhile, experimental data from practical project are added to validate the simulation results. The experimental results fit well with the simulation results, as shown in Table 3. The optimal position is suitable for multiple turbines in a large wind farm. This conclusion can be used to study a larger amount of turbines in a large farm. 


\section{CONCLUSIONS}

The wake effect of Savonius-type vertical axis wind turbines is investigated using CFD method. Based on Kriging Method, the response surface model is established to define the relationship between optimization objective $C_{p}$ (power coefficient) and layout parameters. PSO algorithm is presented to obtain the optimal position of the downstream turbine. Previous relative essays and results are committed to reducing the interaction effect between different turbines. In other words, the wake of the upstream turbine should not overlap with the downstream turbine. However, a new thought is put forward to reuse the wake energy in the current study. The high speed zone in the wake created by the upstream turbine could be reused to enhance the performance of downstream turbines. Therefore, wind energy is fully utilized. Detailed conclusions can be summarized as follows:

1) The power coefficient $C_{p}$ of the downstream turbine changes with the layout position. On the returning blade side, the optimal layout position of the downstream turbine is $x=4.91$ and $y=2.24$. Correspondingly, the optimal $C_{p}$ is 0.2913 . While on the advancing blade side, the optimal position is $x=5.25$ and $y=-2.18$. The optimal $C_{p}$ is 0.3044 . The optimal layout on the advancing blade side is visibly superior to that of on the returning blade side.

2) The optimal layout position is located in the periodic high speed zone. In this zone, the averaged incoming flow speed for the downstream turbine increases obviously. The performance of the downstream turbine is improved in a whole rotation period. It is noteworthy that, for a typical layout, in which the returning blade located in low speed zone and the advancing blade located in the periodic high speed zone, the performance of the downstream turbine is just improved in returning process.

3) When the distance between the upstream turbine and the downstream turbine is relatively small, multi-turbines interaction effect cannot be ignored. The performance of the upstream turbine could be largely affected by the downstream turbine. With the distance increasing, the $C_{p}$ of the upstream wind turbine increases. When the distance is longer than a certain distance, the interaction effect on the upstream turbine could be neglected. In the current study, the optimal layout position exceeds the certain distance.

4) The optimal layout position of the downstream turbine could be applicable for multi-turbines layout. As the number of downstream turbines increases, all power properties are improved. $C_{\mathrm{p}}$ of each downstream turbine is close to predictive value $\left(C_{\mathrm{p}}=0.30722\right)$.

5) In practice, more turbines can be extended as shown in Fig. 22. Compared with past research, multi-turbines layout can be more closely spaced. In equal surfaces, the number of turbines using the new layout method is about 4 times larger than the number of turbines using conventional no overlap layout method.

In this study, it is intended to provide a novel wake energy reuse ideology for the layout optimization of Savonius-type vertical axis wind turbines in a large wind farm. Using this method, the wake energy caused by the upstream turbine is not detrimental to downstream turbines. On the contrary, the wake energy is used to enhance the performance of downstream turbine. Therefore, applying the wake energy reuse method in VAWT layout optimization is worthy of research and promotion in the future. 


\section{ACKNOWLEDGEMENT}

This research is supported by the National Science Foundation of China (Grant No. 61572404) and the Science and Technology Nova Plan of Shaanxi Province (Grant No. 2016KJXX-57).

\section{REFERENCES}

[1] Zuo W, Wang X, Kang S. Numerical simulations on the wake effect of h-type vertical axis wind turbines. Energy 2016;106: 691-700.

[2] Gao X, Yang H, Lu L. Optimization of wind turbine layout position in a wind farm using a newly-developed two-dimensional wake model. Applied Energy 2016;174:192-200.

[3] Mo JO, Choudhry A, Arjomandi M, Lee YH. Large eddy simulation of the wind turbine wake characteristics in the numerical wind tunnel model. Journal of Wind Engineering and Industrial Aerodynamics 2013;112:11-24.

[4] Guerri O, Sakout A, Bouhadef K. Simulations of the fluid flow around a rotating vertical axis wind turbine. Wind Engineering 2007;31(3): 149-163.

[5] Park J, Law K H. Layout optimization for maximizing wind farm power production using sequential convex programming. Applied Energy 2015;151:320-334.

[6] Kacprzak K, Liskiewicz G, Sobczak K. Numerical investigation of conventional and modified Savonius wind turbines. Renewable Energy 2013; 60(4):578-585.

[7] Whitehouse GR, Sibilia MJ, Bilanin AJ, et al. Variable geometry wind turbine for performance enhancement, improved survivability and reduced cost of energy. Wind Energy 2015; 18(7): 1303-1311.

[8] Altan, Deda B, Atılgan. An experimental study on improvement of a Savonius rotor performance with curtaining. Experimental Thermal and Fluid Science 2008; 32(8):1673-1678.

[9] Tian W, Ozbay A, Hu H. Effects of incoming surface wind conditions on the wake characteristics and dynamic wind loads acting on a wind turbine model. Physics of Fluids 2014; 26(12), 1073-1079.

[10] Leu TS, Yu JM, Hu CC, Miau JJ, Liang SY, Li JY. Experimental study of free stream turbulent effects on dynamic stall of pitching airfoil by using particle image velocimetry. Applied Mechanics \& Materials 2012; 225:103-108.

[11] Rockel S, Peinke J, Hölling M, Cal RB. Wake to wake interaction of floating wind turbine models in free pitch motion: an eddy viscosity and mixing length approach. Renewable Energy 2016; 85:666-676.

[12] Chamorro LP, Portéagel F. Turbulent flow inside and above a wind farm: a wind-tunnel study. Energies 2011; 4(12):1916-1936.

[13] Martin JD, Simpson TW. Use of kriging models to approximate deterministic computer models. AIAA journal 2005; 43(4): 853-863.

[14] Eberhart RC, Kennedy J. A new optimizer using particle swarm theory. In Proceedings of the sixth international symposium on micro machine and human science, 1995, October; Vol.1, pp. 39-43. 
[15] Kacprzak K., Liskiewicz G, Sobczak K. Numerical investigation of conventional and modified savonius wind turbines. Renewable Energy 2013; 60(4), 578-585.

[16] Kamoji MA., Kedare SB, Prabhu SV. Experimental investigations on single stage modified savonius rotor. Applied Energy 2009; 86(7-8): 1064-1073.

[17] Wenlong T, Baowei S, Zhaoyong M. Conceptual design and numerical simulations of a vertical axis water turbine used for underwater mooring platforms. International Journal of Naval Architecture and Ocean Engineering 2013; 5(4): 625-634.

[18] Akwa JV, Vielmo HA, Petry AP. A review on the performance of Savonius wind turbines. Renewable and Sustainable Energy Reviews 2012; 16(5): 3054-3064.

[19] Kacprzak K, Liskiewicz G, Sobczak K. Numerical investigation of conventional and modified Savonius wind turbines. Renewable energy 2013; 60: 578-585.

[20] McTavish S, Feszty D, Sankar T. Steady and rotating computational fluid dynamics simulations of a novel vertical axis wind turbine for small-scale power generation. Renewable energy 2012; 41: 171-179.

[21] Altan BD, Atilgan M. An experimental and numerical study on the improvement of the performance of savonius wind rotor. Energy Conversion and Management 2008; 49(12):3425-3432.

[22] Sheldahl RE, Feltz LV, Blackwell BF. Wind tunnel performance data for two-and three-bucket Savonius rotors. Journal of Energy 1978; 2(3): 160-164.

[23] Sun C, Song B, Wang P. Parametric geometric model and shape optimization of an underwater glider with blended-wing-body. International Journal of Naval Architecture and Ocean Engineering, 2015, 7(6): 995-1006.

[24] Chen HN, Zhu YL, Hu KY, et al. Global optimization based on hierarchical coevolution model. Evolutionary Computation 2008. CEC 2008. (IEEE World Congress on Computational Intelligence). IEEE Congress on. IEEE, 2008: 1497-1504.

[25] Jaohindy P, Ennamiri H, Garde F, et al. Numerical investigation of airflow through a Savonius rotor. Wind Energy 2013; 17(6):2-18.

[26] Shigetomi A, Murai Y, Tasaka Y, Takeda Y. Interactive flow field around two savonius turbines. Renewable Energy 2011; 36(2):536e45. 
Fig. 1 (a) Migrating geese and (b) Wake of a single turbine

Fig. 2 (a) One side type layout and (b) V type layout

Fig. 3 (a) Savonius wind turbines and (b) Simplified 2D model

Fig. 4 Computational domains

Fig. 5 Grids of rotating domain and details

Fig. 6 (a) 3 mesh densities and (b) 4 time steps: Comparison of the torque coefficient in a rotation period

Fig. 7 Comparison of the average $C_{\mathrm{p}}$ at different TSR

Fig. 8 Velocity distributions of the wake

Fig. 9 Turbulence Kinetic Energy distributions of the wake

Fig.10 Comparison of (a) $C_{\mathrm{T}}$ of a turbine, (b) $C_{\mathrm{T}}$ of a single blade and (c) Average $C_{\mathrm{p}}$

Fig. 11 The general procedure of PSO

Fig. 12 (a) Response surface and (b) Optimal point on the returning blade side

Fig. 13 (a) Response surface and (b) Optimal point on the advancing blade side

Fig. 14 Simplified wake structure

Fig. 15 Velocity distribution at a typical layout position

Fig. 16 The variations of instantaneous $C_{\mathrm{T}}$ of (a)Blade 1, (b)Blade 2 and (c)Turbine

Fig. 17 Velocity distribution at the optimal layout position

Fig. 18 The variations of instantaneous $C_{\mathrm{T}}$ of (a)Blade 1, (b)Blade 2 and (c)Turbine

Fig. 19 Pressure distributions around the downstream turbine at optimal layout position

Fig. 20 Comparison of pressure distributions on a single blade at different rotor angle position

Fig. 21 (a) Response surface of $C_{\mathrm{p}}$ for the upstream turbine and (b) Region of interaction effect

Fig. 22 Velocity distributions at optimal layout position for multi-turbines

Fig. 23 Comparison of (a) $C_{\mathrm{T}}$ of a single blade and (b) average $C_{\mathrm{p}}$ for multi-turbines
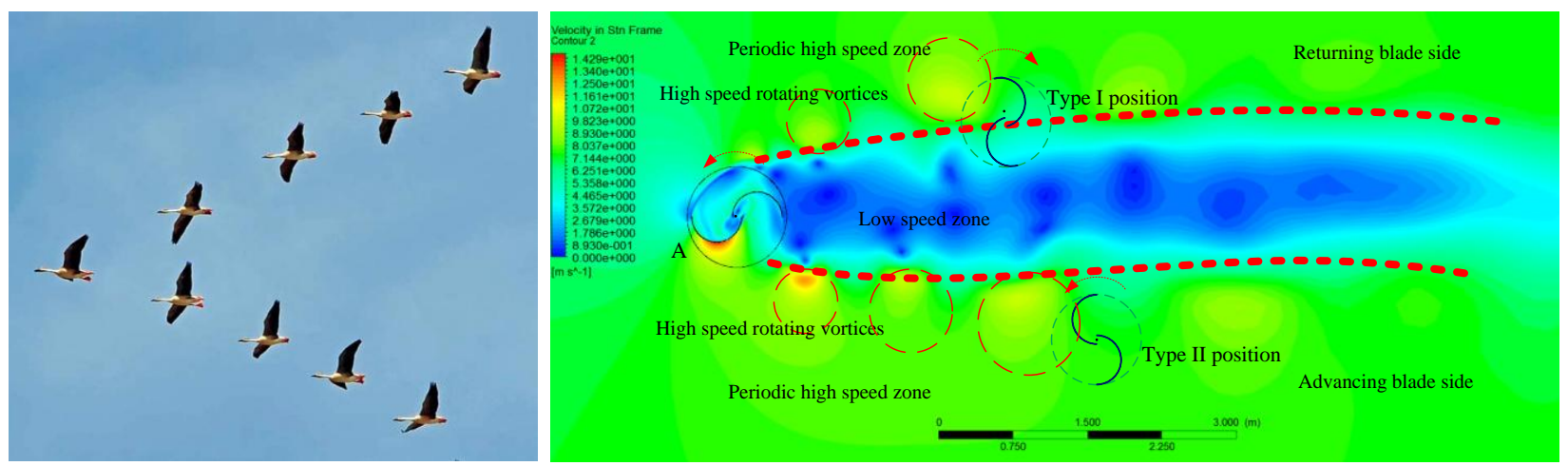

Fig. 1 (a) Migrating geese and (b) Wake of a single turbine 

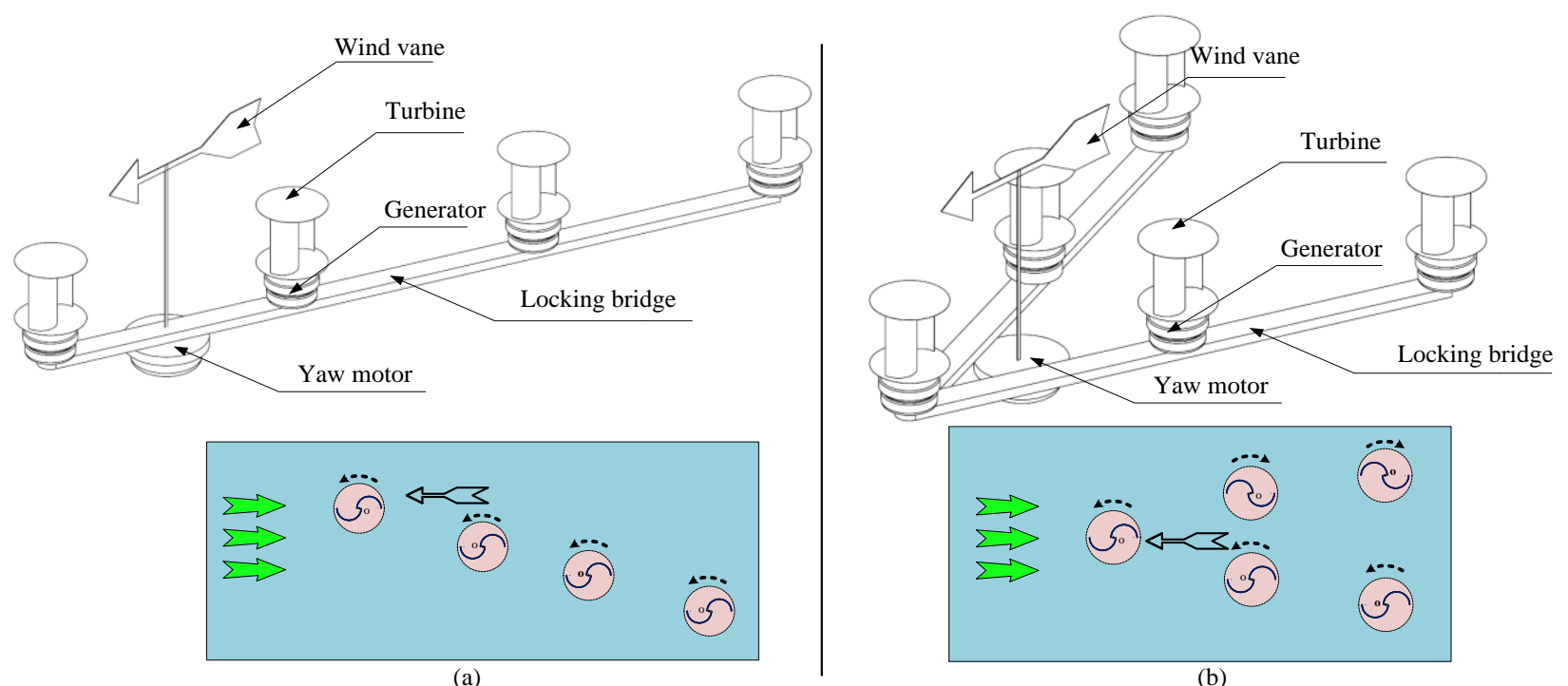

(a)

$\cdots$

๑

Fig. 2 (a) One side type layout and (b) V type layout

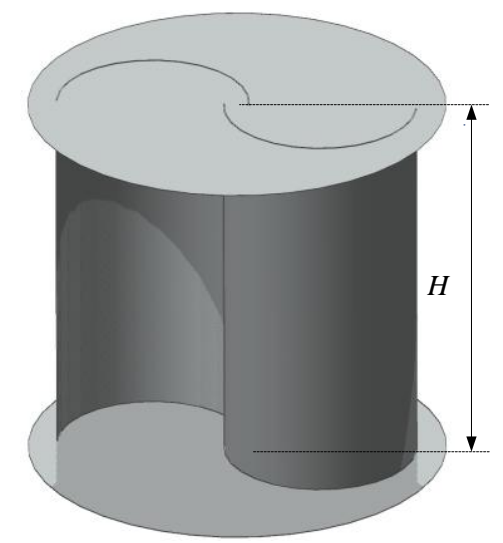

(a) Savonius turbines with endplates

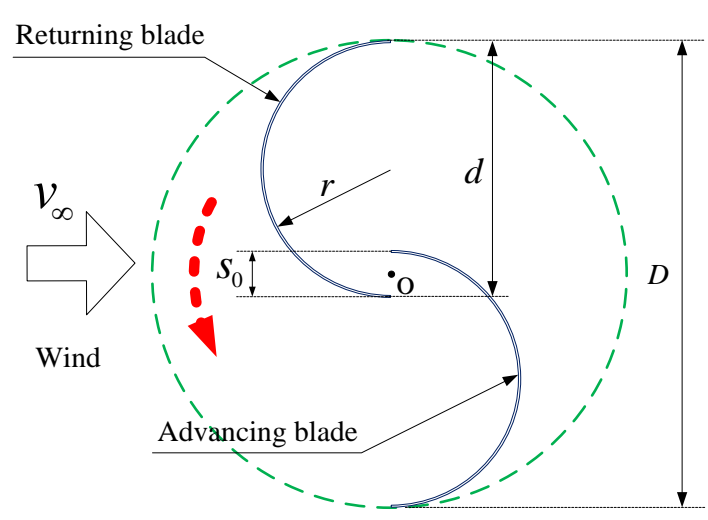

(b) Classical Savonius

Fig. 3 (a) Savonius wind turbines and (b) Simplified 2D model 


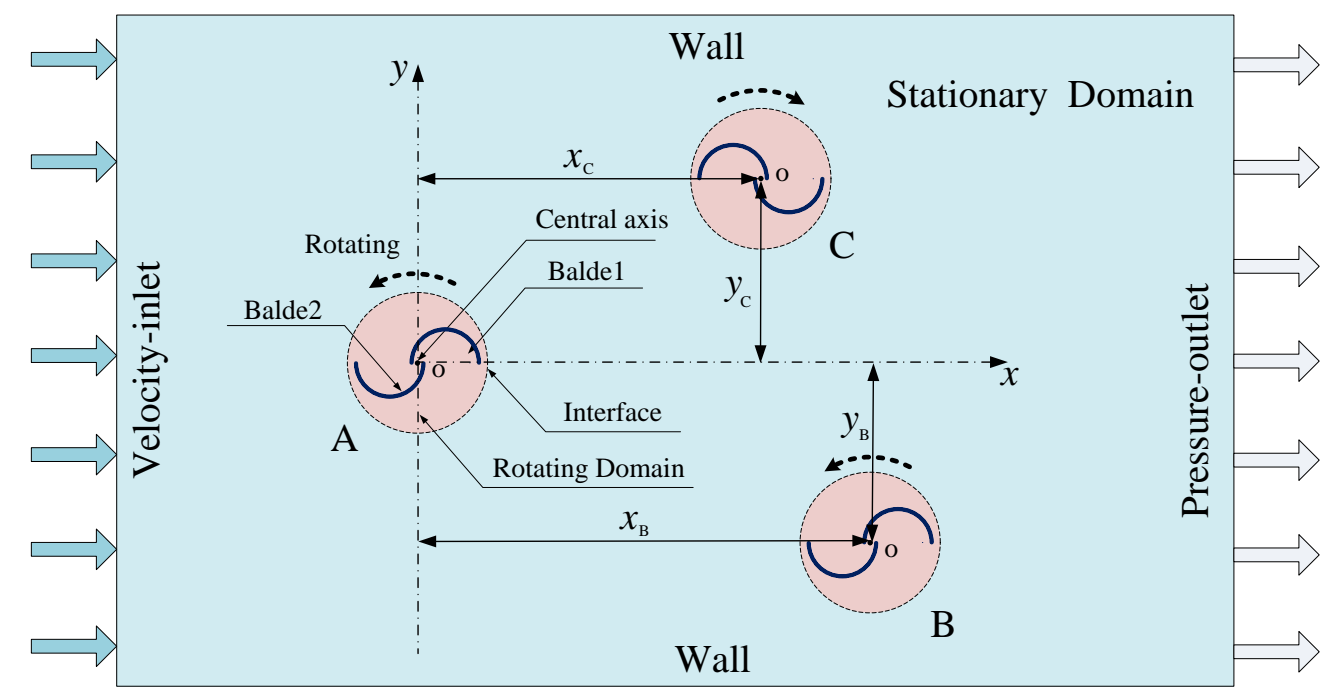

Fig. 4 Computational domains
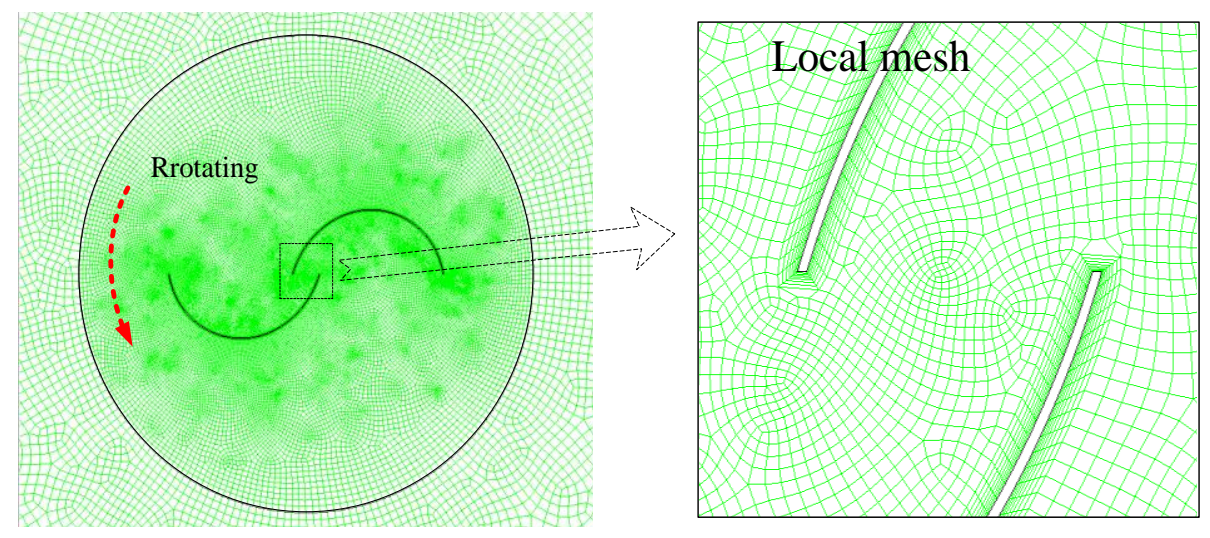

Fig. 5 Grids of rotating domain and details

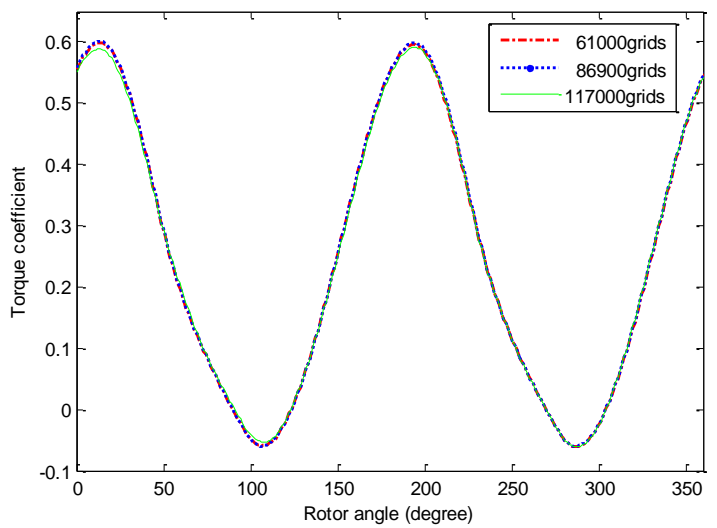

(a) 3 mesh densities

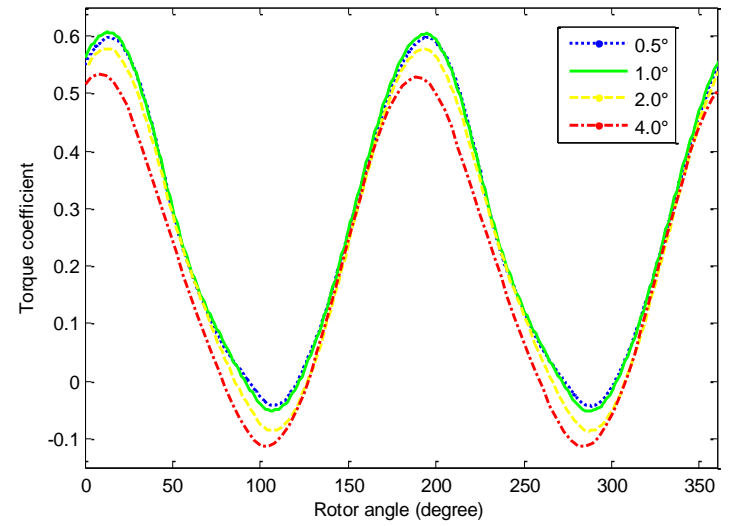

(b) 4 simulated time steps

Fig. 6 (a) 3 mesh densities and (b) 4 time steps: Comparison of the torque coefficient in a rotation period 


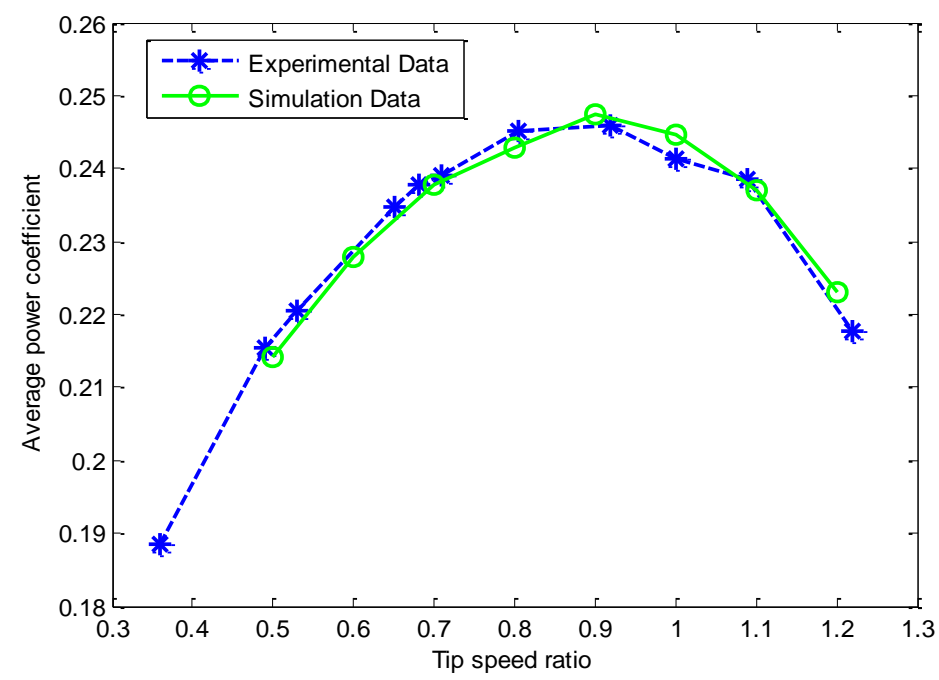

Fig. 7 Comparison of the average $C_{\mathrm{p}}$ at different $T S R$

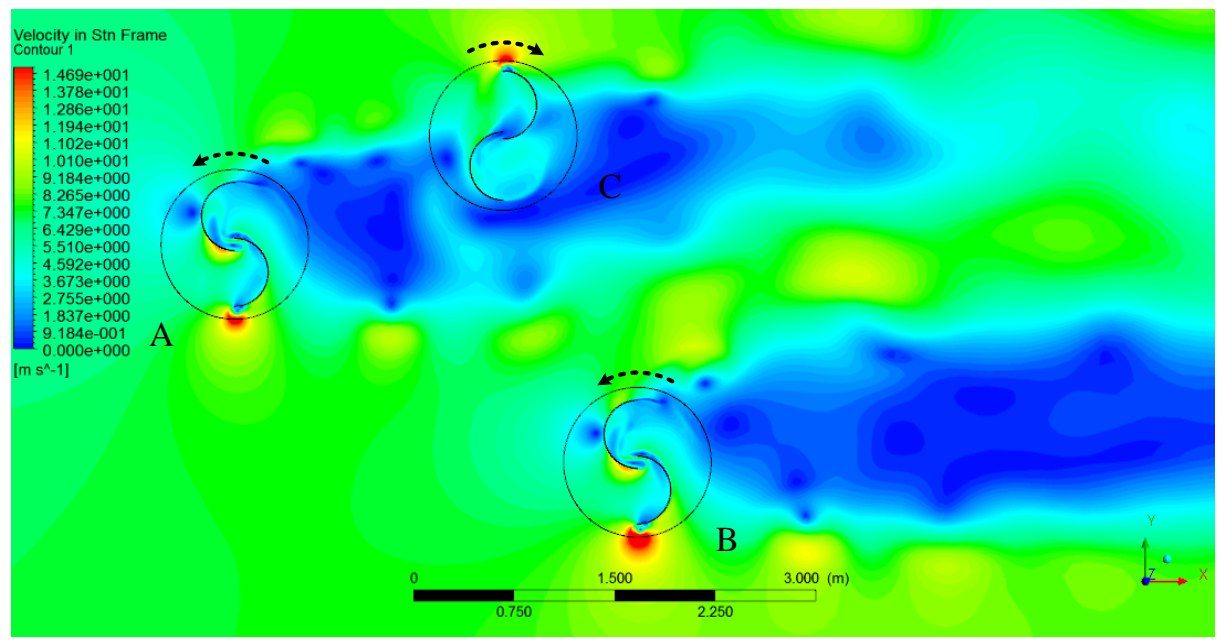

Fig. 8 Velocity distributions of the wake 


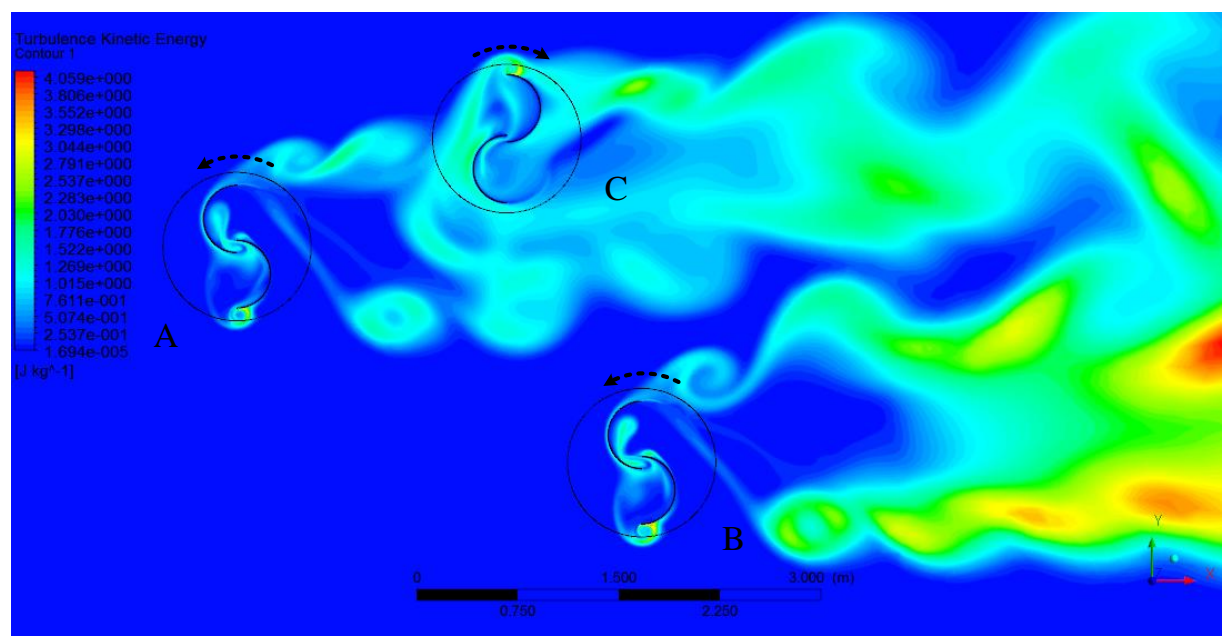

Fig. 9 Turbulence Kinetic Energy distributions of the wake
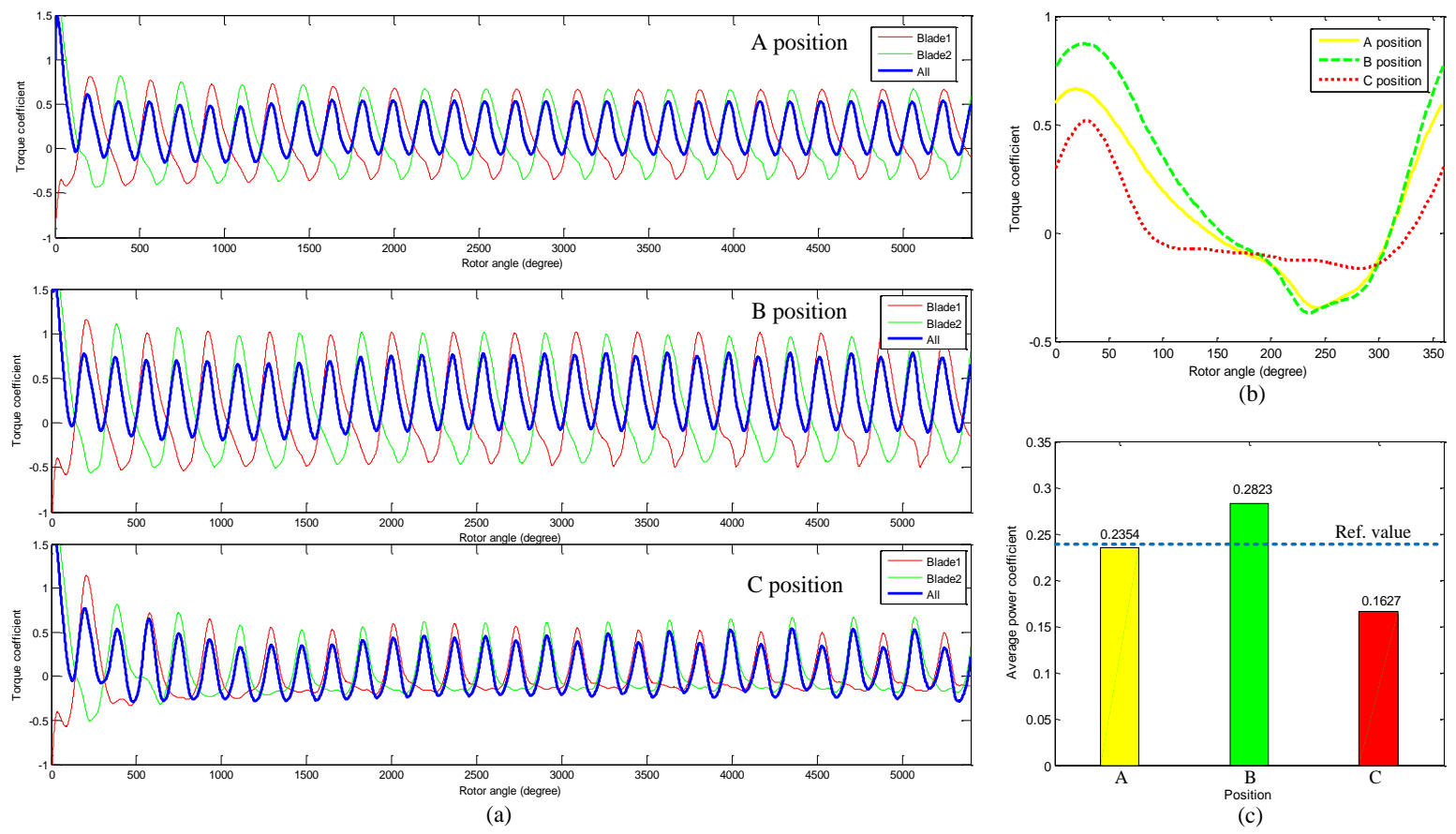

(a)

Fig.10 Comparison of (a) $C_{\mathrm{T}}$ of a turbine, (b) $C_{\mathrm{T}}$ of a single blade and (c) Average $C_{\mathrm{p}}$ 


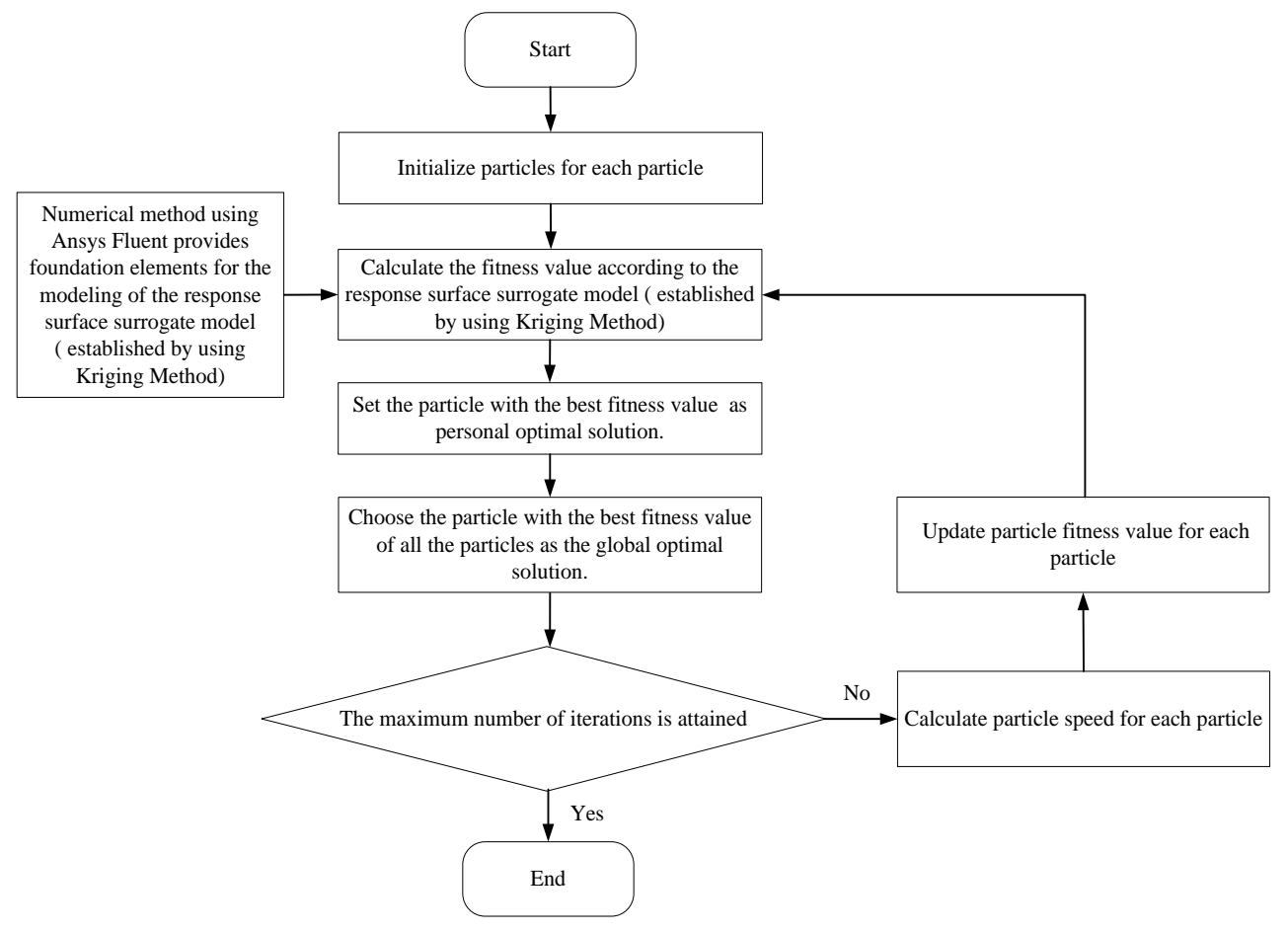

Fig. 11 The general procedure of PSO

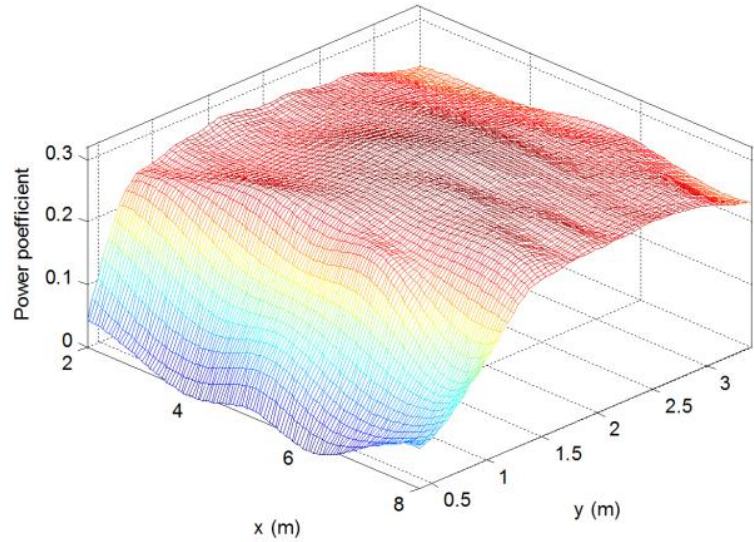

(a)

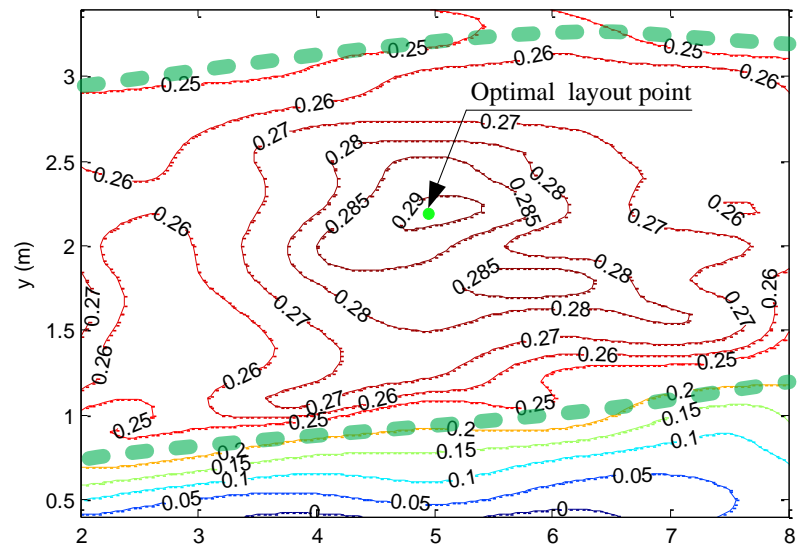

(b)

Fig. 12 (a) Response surface and (b) Optimal point on the returning blade side 


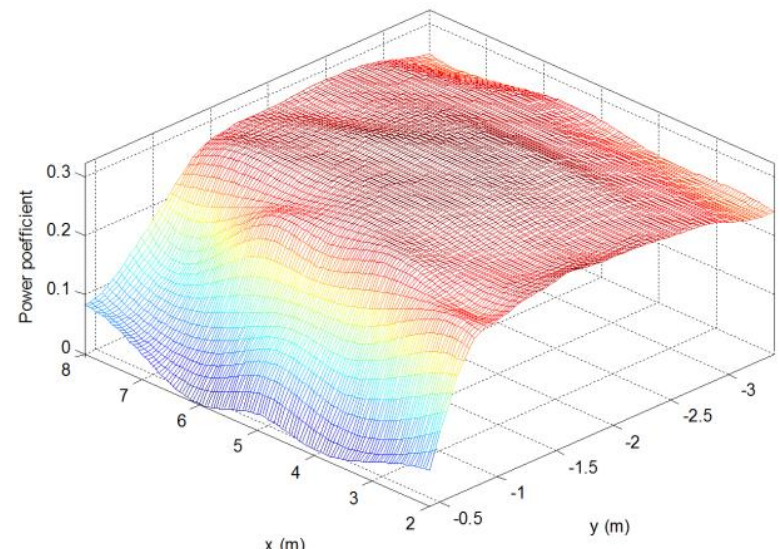

(a)

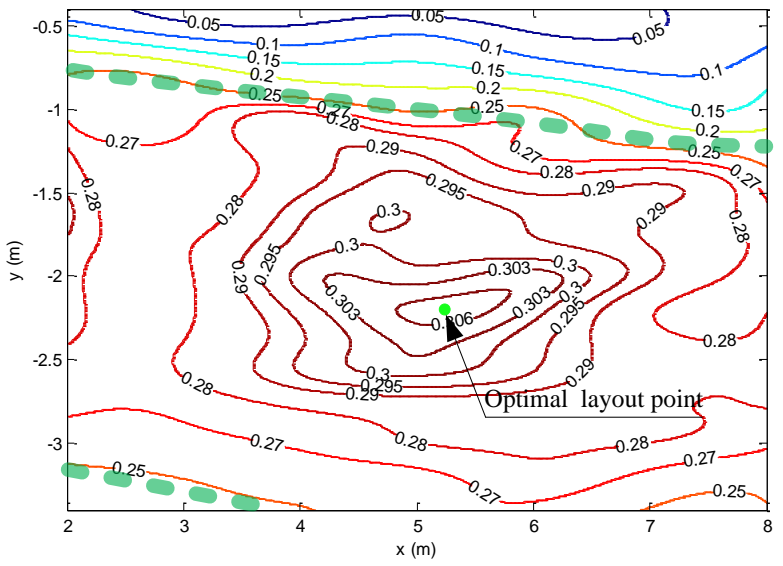

(b)

Fig. 13 (a) Response surface and (b) Optimal point on the advancing blade side

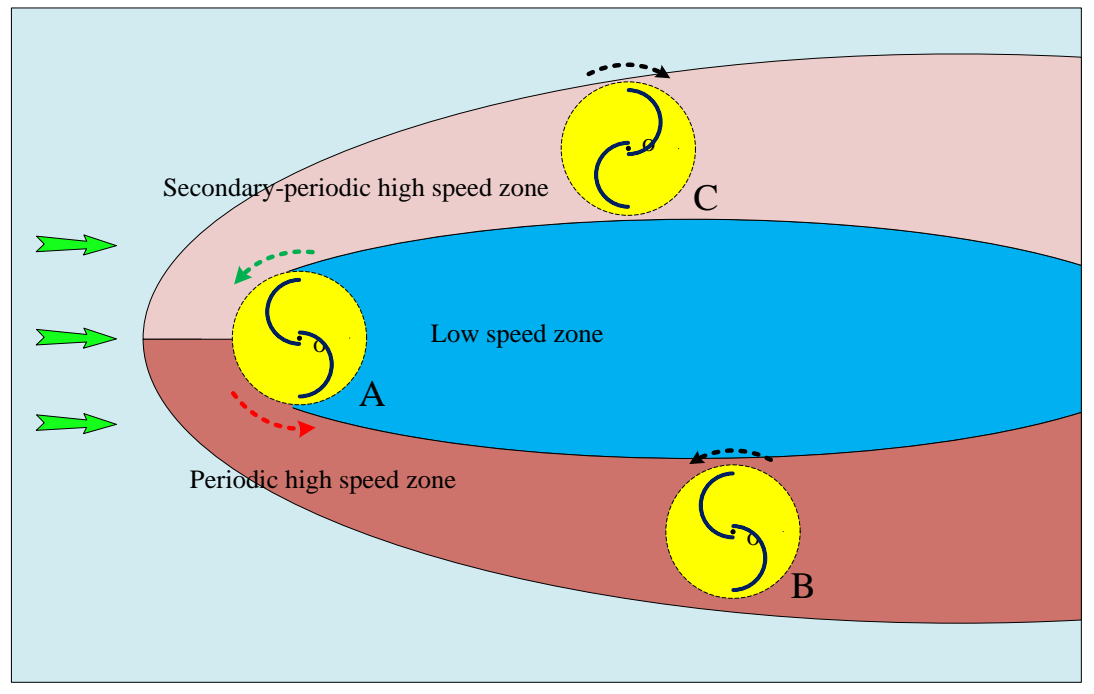

Fig. 14 Simplified wake structure 


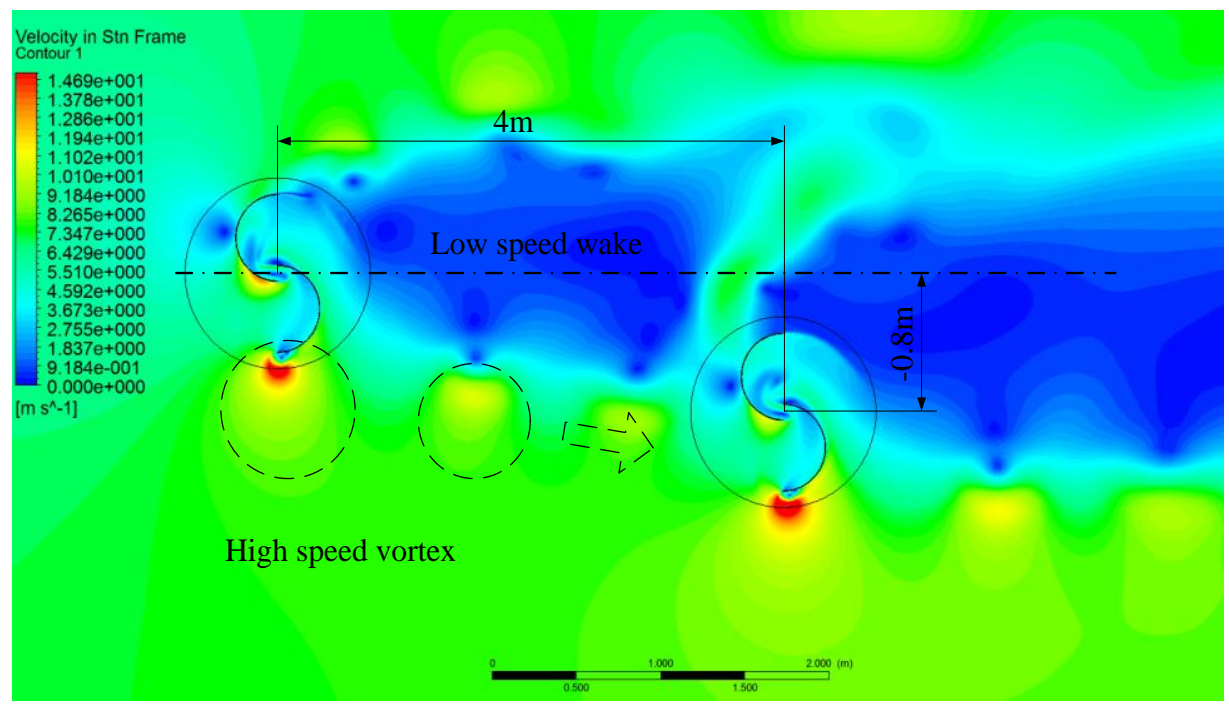

Fig. 15 Velocity distribution at a typical layout position

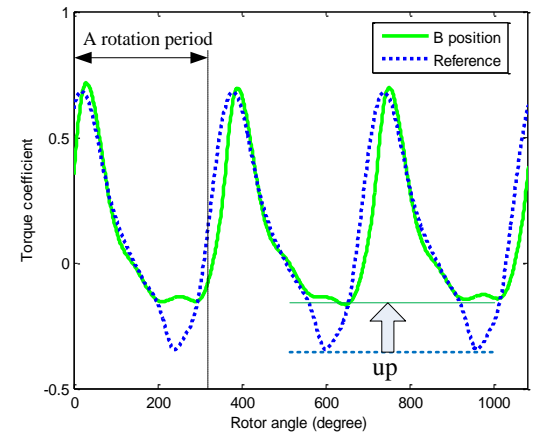

(a)

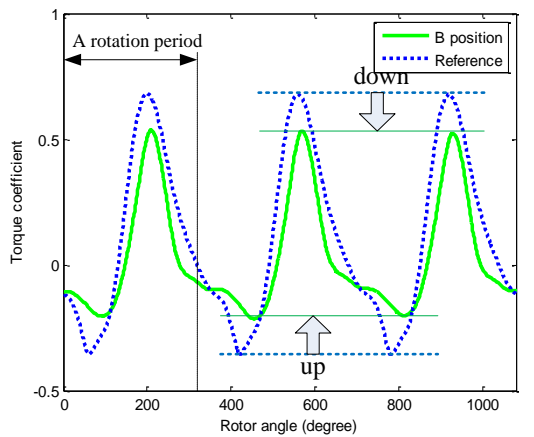

(b)

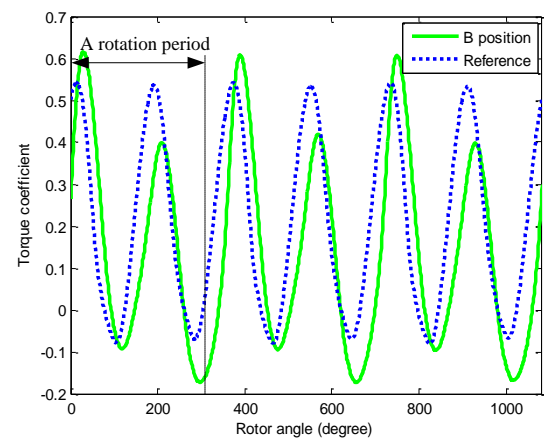

(c)

Fig. 16 The variations of instantaneous $C_{\mathrm{T}}$ of (a)Blade 1, (b)Blade 2 and (c)Turbine

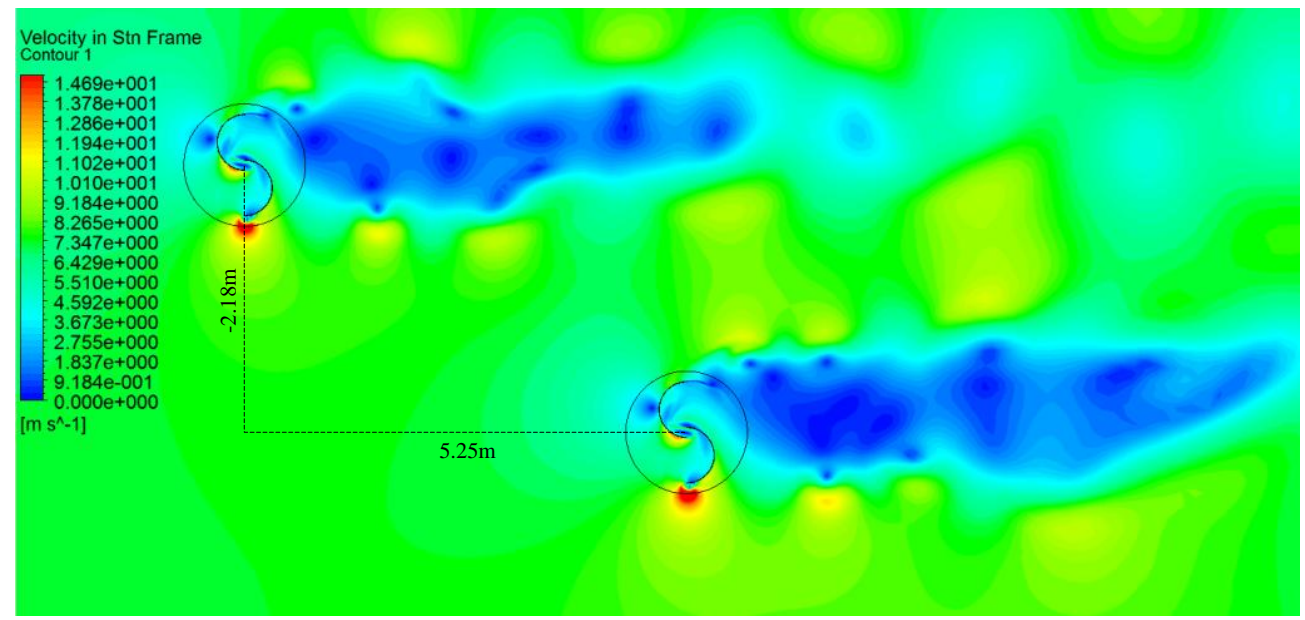

Fig. 17 Velocity distribution at the optimal layout position 


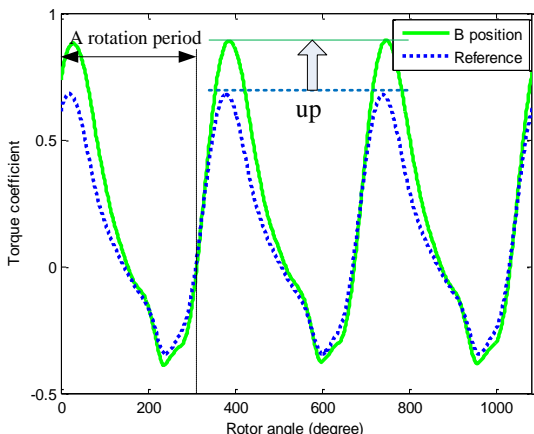

(a)

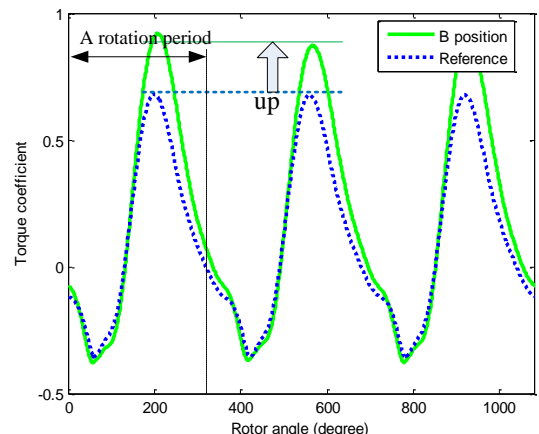

(b)

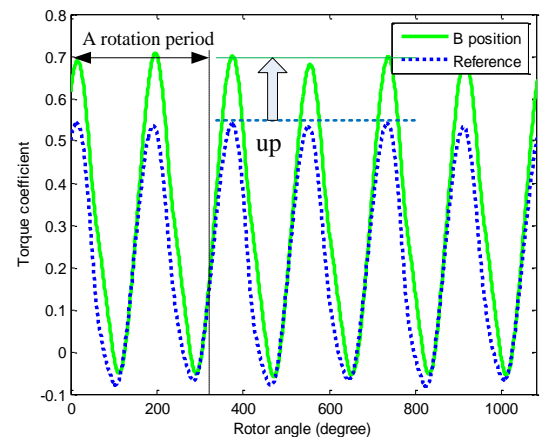

(c)

Fig. 18 The variations of instantaneous $C_{\mathrm{T}}$ of (a)Blade 1, (b)Blade 2 and (c)Turbine

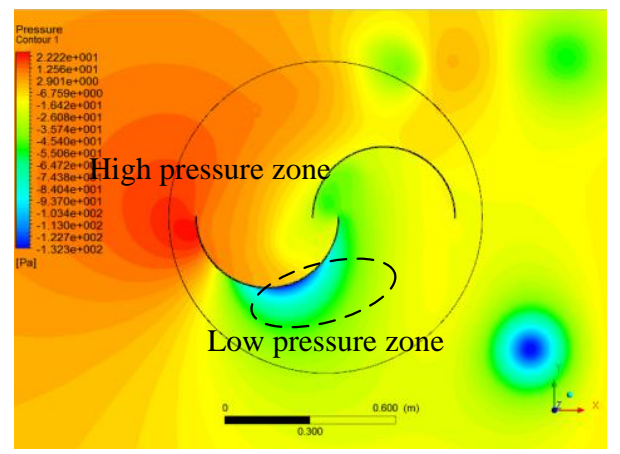

(a) $0^{\circ}$

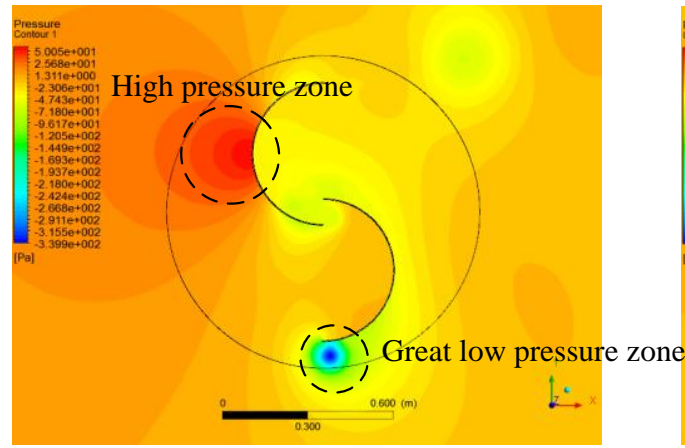

(c) $90^{\circ}$

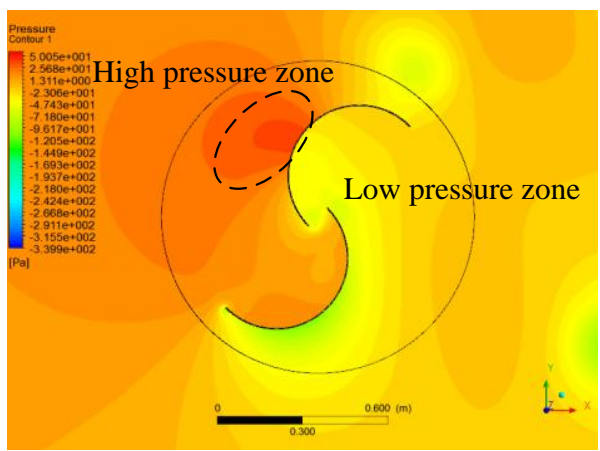

(b) $45^{\circ}$

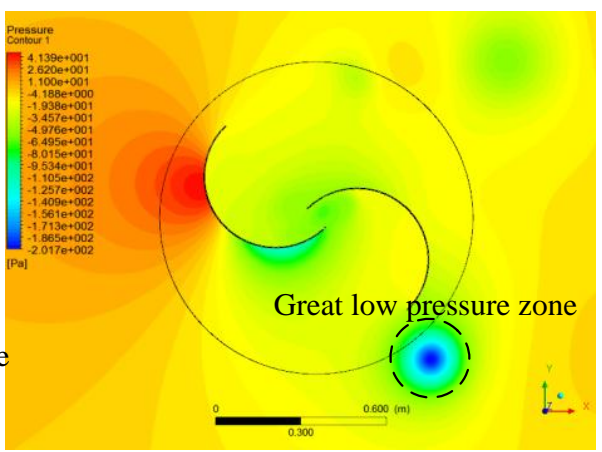

(d) $135^{\circ}$

Fig. 19 Pressure distributions around the downstream turbine at optimal layout position 


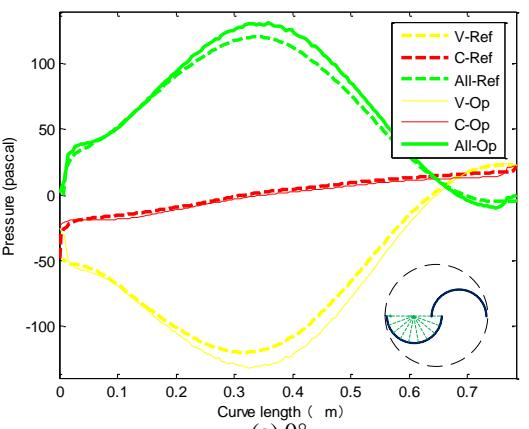

(a) $0^{\circ}$

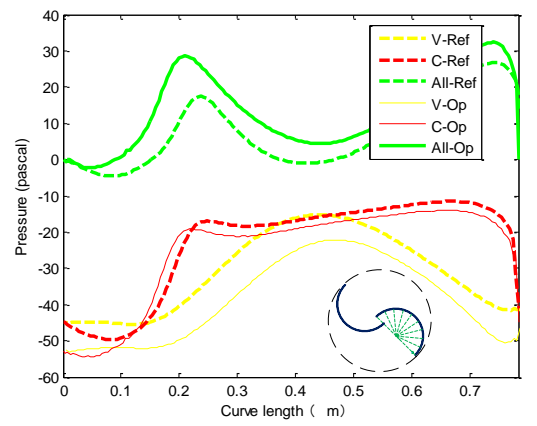

(d) $135^{\circ}$

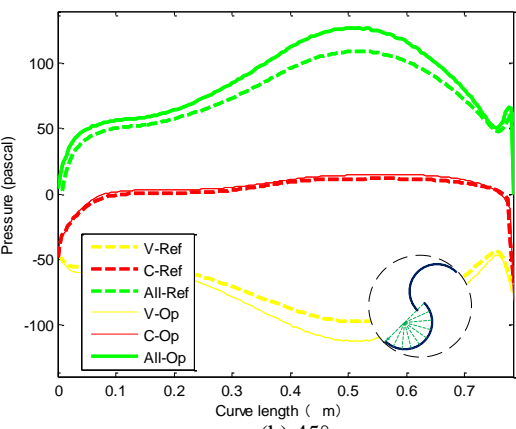

(b) $45^{\circ}$

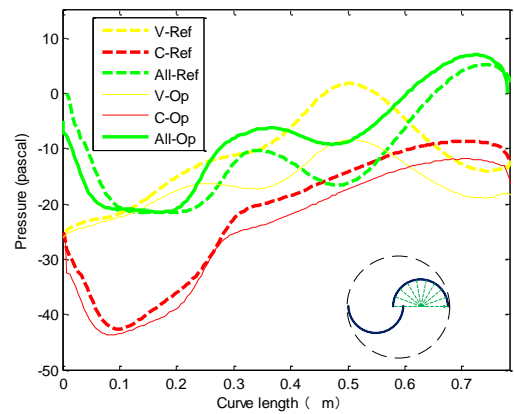

(e) $180^{\circ}$

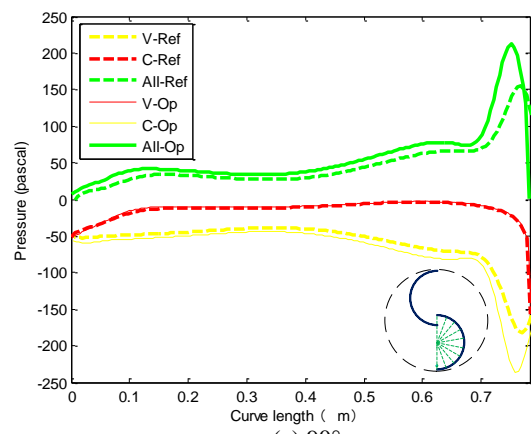

(c) $90^{\circ}$

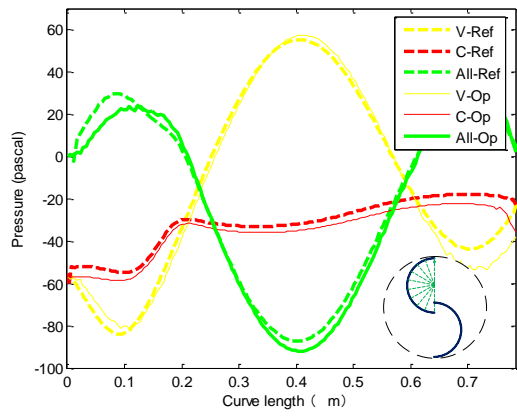

(f) $270^{\circ}$

Fig. 20 Comparison of pressure distributions on a single blade at different rotor angle position

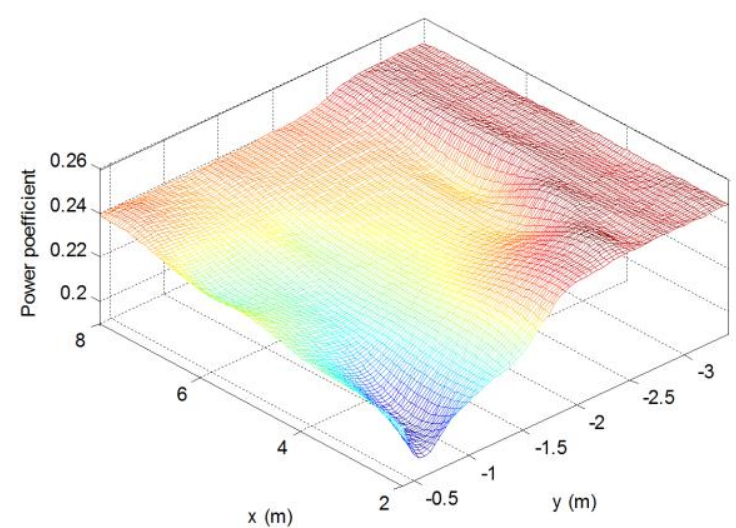

(a)

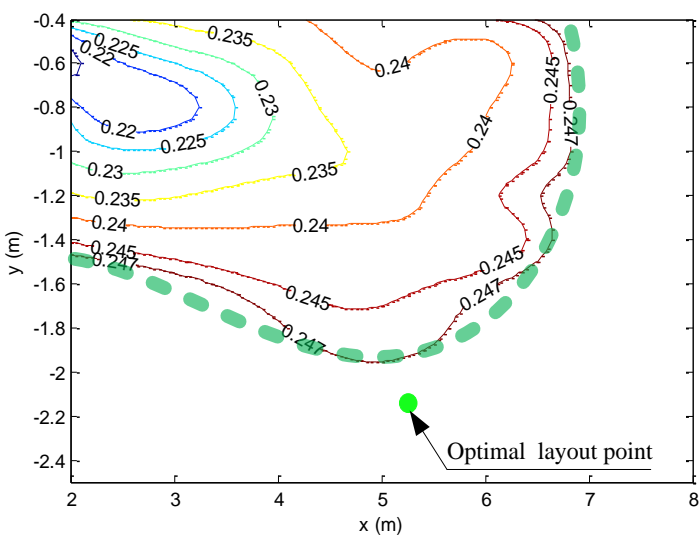

(b)

Fig. 21 (a) Response surface of $C_{\mathrm{p}}$ for the upstream turbine and (b) Region of interaction effect 


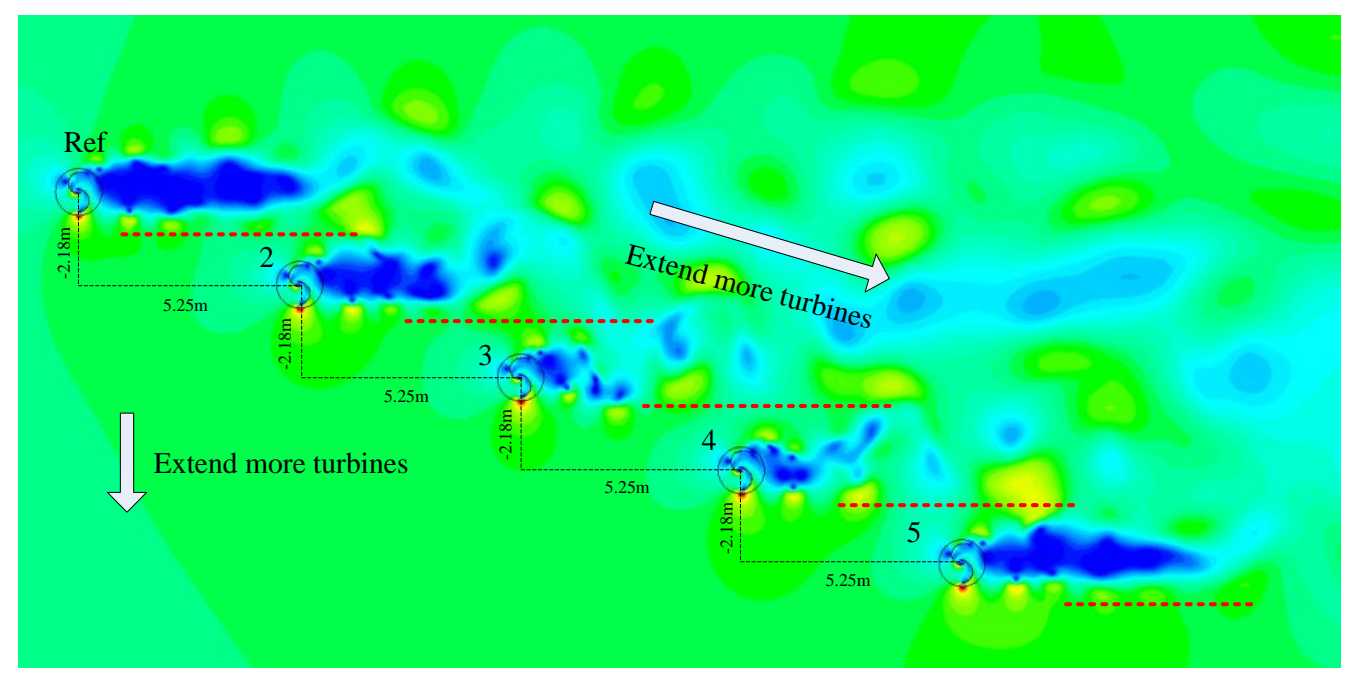

Fig. 22 Velocity distributions at optimal layout position for multi-turbines
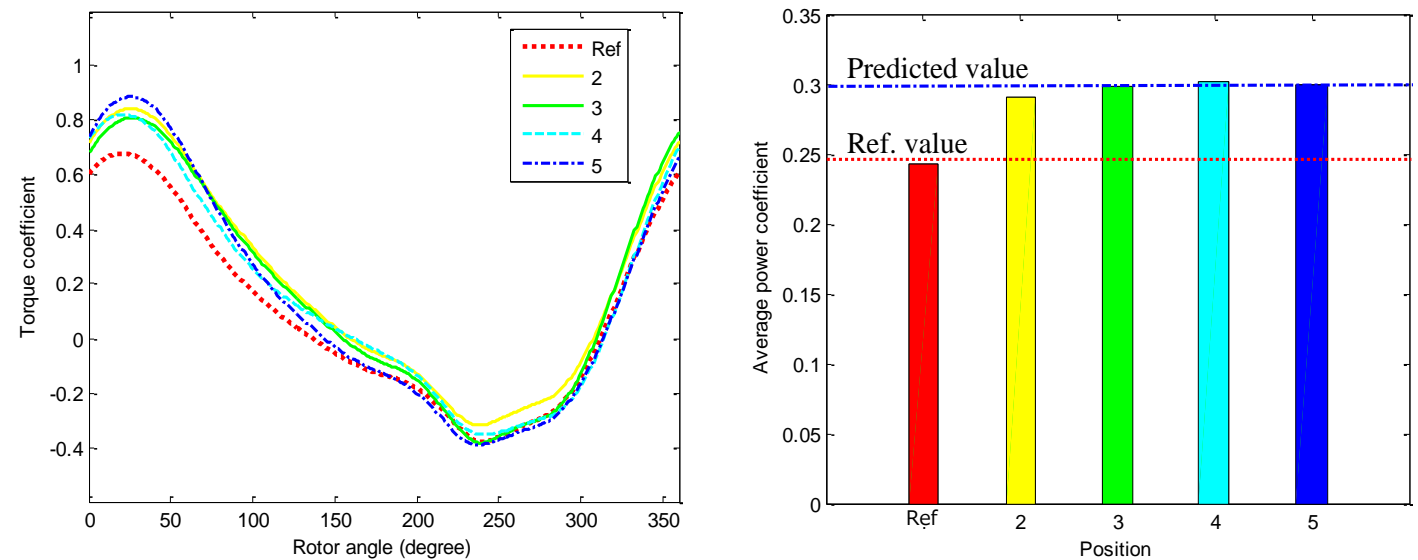

Fig. 23 Comparison of (a) $C_{\mathrm{T}}$ of a single blade and (b) average $C_{\mathrm{p}}$ for multi-turbines 
Table 1 Main geometrical parameters of turbine

\begin{tabular}{lllllll}
\hline & $D(\mathrm{~m})$ & $H$ & $(\mathrm{~m})$ & $d(\mathrm{~m})$ & $S_{0}(\mathrm{~m})$ & $r \quad(\mathrm{~m})$ \\
\hline Savonius & 0.909 & 1.0 & 0.5 & 0.91 & 0.25 \\
\hline
\end{tabular}

Table 2 Comparison of main performance parameters

\begin{tabular}{lllll}
\hline & Optimal layout & Predictive value of $C_{p}$ & Experiment value of $C_{p}$ & Optimization effect \\
\hline Ref. value & -- & -- & 0.2477 & -- \\
Returning side & $\mathrm{x}=4.91 ; \mathrm{y}=2.24$ & 0.29116 & 0.2913 & $17.60 \%$ \\
Advancing side & $\mathrm{x}=5.25 ; \mathrm{y}=-2.18$ & 0.30722 & 0.3044 & $22.89 \%$ \\
\hline
\end{tabular}

Table 3 Comparison between experimental results and simulation results

\begin{tabular}{llllll}
\hline & Ref & $\# 2$ & $\# 3$ & $\# 4$ & $\# 5$ \\
\hline Experiment & 0.239 & 0.281 & 0.303 & 0.293 & 0.290 \\
Simulation & 0.24324 & 0.29033 & 0.30597 & 0.29947 & 0.30164 \\
\hline
\end{tabular}

